\title{
Reversible Environmental Catastrophes with Disconnected Generations
}

\author{
Ben J. Heijdra ${ }^{1,2,3} \cdot$ Pim Heijnen ${ }^{1}$
}

Accepted: 27 October 2020 / Published online: 11 November 2020

(c) The Author(s) 2020

\begin{abstract}
We study environmental policy in a stylized economy-ecology model featuring multiple deterministic stable steady-state ecological equilibria. The economy-ecology does not settle in either of the deterministic steady states as the environmental system is hit by random shocks. Individuals live for two periods and derive utility from the (stochastic) quality of the environment. They feature warm-glow preferences and engage in private abatement in order to weakly influence the stochastic process governing environmental quality. The government may also conduct abatement activities or introduce environmental taxes. We solve for the market equilibrium abstracting from public abatement and taxes and show that the ecological process may get stuck for extended periods of time fluctuating around the heavily polluted (low quality) deterministic steady state. These epochs are called environmental catastrophes. They are not irreversible, however, as the system typically switches back to the basin of attraction associated with the good (high quality) deterministic steady state. The paper also compares the stationary distributions for environmental quality and individuals' welfare arising under the unmanaged economy and in the first-best social optimum.
\end{abstract}

Keywords Ecological thresholds · Nonlinear dynamics · Environmental policy · Abatement · Capital taxes

JEL Classification D60 $\cdot$ E62 $\cdot \mathrm{H} 23 \cdot \mathrm{H} 63 \cdot \mathrm{Q} 20 \cdot \mathrm{Q} 28 \cdot \mathrm{Q} 50$

This paper was presented at the 14th Viennese Conference on Optimal Control and Dynamic Games 2018 (3-6 July 2018) and at the CeNDEF@20 workshop (Amsterdam, 18-19 October 2018).

Electronic supplementary material The online version of this article (https://doi.org/10.1007/s1064 5-020-09378-7) contains supplementary material, which is available to authorized users.

Ben J. Heijdra

b.j.heijdra@rug.nl

Extended author information available on the last page of the article 


\section{Introduction}

"The window within which we may limit global temperature increases to 2 ${ }^{\circ} \mathrm{C}$ above preindustrial times is still open, but is closing rapidly. Urgent and strong action in the next two decades [...] is necessary if the risks of dangerous climate change are to be radically reduced."

Nicholas Stern, Why Are We Waiting? (2015, p. 32)

“ ...we are entering the Climate Casino. By this, I mean that economic growth is producing unintended but perilous changes in the climate and earth systems [which] will lead to unforeseeable and probably dangerous consequences. We are rolling the climatic dice, the outcome will produce surprises, and some of them are likely to be perilous. But we have just entered the Climate casino, and there is still time to turn around and walk back out."

William Nordhaus, The Climate Casino (2013, pp. 3-4)

“...I am a climate lukewarmer. That means I think recent global warming is real, mostly man-made and will continue but I no longer think it is likely to be dangerous and I think its slow and erratic progress so far is what we should expect in the future."

Matt Ridley, The Times newspaper (January 19, 2015)

Public commentators on climate change and, more generally, on current and future environmental issues seem to come in only two flavors. On the one hand, climate sceptics like bestselling popular science writer Matt Ridley and political scientist Bjørn Lomborg (and many others) tend to downplay the dangers and may even point at positive aspects of global warming. On the other hand, prominent environmental economists have assumed the mantle of whistle-blower and stress the immense risks current generations take with their own and future generations' environment and welfare. One of the reasons why no consensus has emerged up to this point is, of course, due to the fact that in normal times environmental changes are only gradual and slow (compared to an individual's life-span) and because the future is inherently stochastic and thus unknowable with certainty.

In this paper we present an explorative study in which we sketch what we consider to be important elements in the long-term evolution of the intertwined economic and ecological systems. In order to bring some structure to the debate we identify what we consider to be the four most crucial principles of model-based environmental policy analysis.

P1 Generations are the relevant units of analysis. Sustainability is defined in the Brundtland Report (World Commission on Environment and Development 1987, p. 43) as follows: "Sustainable development is development that meets the needs of the present without compromising the ability of future generations to meet their own needs." This suggests that the evaluation of environmental policy 
should be conducted in the context of an overlapping generations model with disconnected generations.

P2 Abrupt environmental changes are possible. In recent years ecologists have discovered that nature does not always respond smoothly to gradual changes but instead may exhibit so-called "tipping points" in which dramatic environmental disasters occur (Scheffer et al. 2001). Environmental economists have adopted the possibility of non-linearities in the response of the environmental system to economic developments. For a recent symposium on the economics of tipping points, see de Zeeuw and Li (2016).

P3 Both the economy and the ecological system are inherently stochastic. Indeed, as is stressed by both Stern and Nordhaus in the quotes given above, global warming should not be seen as a deterministic process but rather should be recognized as being inherently stochastic in nature. A suitable model of environmental policy must thus explicitly recognize the fact that both private and public decision making takes place in a world hit by random shocks.

P4 Individuals care for the environment but not very strongly. On the one hand, environmental quality has strong public good features so that rational individuals tend to free ride on it. On the other hand, we believe that (at least some) people do get a "warm glow" from cleaning up their local parks and beaches, even if it is merely to be seen "doing the right thing" by their neighbours and friends. A modest amount of private abatement does take place in reality and we capture this phenomenon by adopting the insights of Andreoni $(1988,1989,1990)$ and Andreoni and Levinson (1990).

The objective of this paper is to study environmental policy using a highly stylized conceptual model which can accommodate all principles (P1)-(P4) simultaneously. In order to capture Principle (P1) we employing an explicit general equilibrium overlapping-generations framework of the economy-ecology interaction. By adopting a closed-economy perspective we capture the notion of global interactions between the economy and the environment. We also assume that the generations of cohorts populating the planet are disconnected with each other, i.e. we abstract from voluntary intergenerational transfers from parent to child (and vice versa). The disconnectedness of generations ensures that current generations will not voluntarily provide monetary transfers to future generations to compensate the latter for the environmental sins committed by the former.

In our view, Principle (P1) is absolutely crucial. Barro's (1974) celebrated dynastic model links all generations together via operative bequests and thus eliminates all generational frictions. This would seem to obviate the need for an overlapping-generations model (and to make our principle (P1) redundant). However, as was forcefully argued by Bernheim and Bagwell (1988), the dynastic model must be rejected in the face of its absurd policy conclusions. Indeed, since every agent is dynastically linked with every other agent the model yields a number of neutrality results that are clearly not observed in the real world (such as the irrelevance of public redistribution, distorting taxes, and prices). The disconnectedness of generations is a friction that must be taken into account when formulating an optimal environmental policy. 
Principle ( $\mathrm{P} 2)$ is accommodated by postulating a nonlinear environmental regeneration function which includes tipping points and multiple stable (deterministic) equilibria. In order to avoid modeling environmental policy as a "one-shot game" (in which only one irreversible catastrophe can occur), we assume that the resulting hysteresis in environmental quality is reversible, albeit at potentially very high cost. In technical terms we recast our earlier deterministic and continuous-time studies to a discrete-time stochastic setting. See Heijdra and Heijnen (2013, 2014).

Principle (P3) is captured, though partially, by including stochastic shocks to the state equation for environmental quality. Although random shocks to the economic system are also potentially important to the proper conduct of environmental policy, we abstract from such shocks in the present paper to keep the analysis manageable. By assuming that ecological disasters are potentially reversible (via (P2)), we find that in a stochastic setting multiple low-environmental-quality epochs of varying duration can materialize, something which is impossible in the somewhat restrictive stochastic single-disaster framework of Tsur and Zemel (2006), Polasky et al. (2011), and many others.

Finally, Principle (P4) is included by introducing a "warm-glow" mechanism into the utility function of individual agents. This ensures that utility maximizing individuals engage in a modest amount of private abatement (because it makes them feel good) but otherwise free ride on the abatement activities by other individuals and (potentially) the government. So in our model environmental quality is a nonexcludable and non-rival public good but there is some private provision going on at all times. By construction we assume that the warm-glow motive is relatively weak so that there is typically "too little" environmental abatement in the absence of an active public abatement stance by the government.

The paper is structured as follows. In Sect. 2 we present a deterministic version of our model (and thus exclude Principle (P3) in doing so). Individual live for two periods, youth and old-age, consume in both period, work only in the first period, and enjoy environmental quality in the second period. Explicit saving during youth takes the form of capital accumulation whilst implicit saving occurs in the form of private abatement which augments future environmental quality. Firms use capital and labour to produce a homogeneous commodity which can be used for consumption, private and public abatement, and investment.

In Sect. 3 we assume that the policy maker does neither engage in public abatement nor employs Pigouvian pollution taxes. We label this case the Deterministic Unmanaged Market Economy (DUME). We show that the model can be condensed into a stable two-equation system of difference equations in the capital intensity and environmental quality. Since both private saving and private abatement depend on both state variables, the dynamic system is fully simultaneous so that analytical results are hard to come by. In order to visualize and quantify the key properties of the model we develop a plausible calibration. The numerical model implies that the effect of environmental quality on the macro-economic equilibrium is quite weak unless the ecological system is stuck in a highly polluted state. In "normal times" individuals simply do not care enough about the environment for them to be influenced by even sizeable fluctuations in environmental quality. In this section we consider two prototypical environmental regeneration functions. When the 
feedback between current and future environmental quality is linear then the system will ultimately settle in a unique steady state for the capital intensity and environmental quality. In contrast, when the feedback is described by a nonlinear regeneration function of the right type, then there exist two welfare-rankable steady-state equilibria. Whilst the capital intensity differs little between the two equilibria, in the low-welfare equilibrium environmental quality is rather low whilst it is rather high in the high-welfare equilibrium. To prepare for things to come, Sect. 3 concludes by computing the deterministic (first-best) social optimum (DSO) that is chosen by a dynamically consistent social planner. Not surprisingly, starting from either of the possible equilibria in the DUME state with a nonlinear regeneration function, such a planner will select a transition path that will result in a unique steady state featuring a high level of environmental quality.

Section 4 constitutes the core of our paper. In this section we re-instate Principle (P3) and study the economy-environment interaction in an inherently stochastic setting. In particular we assume that the state equation for environmental regeneration is hit by random shocks and that the regeneration function is nonlinear and features tipping points. During youth, individuals face uncertainty about the environmental quality they will enjoy during old-age and they take this into account when making optimal decisions concerning saving, consumption, and private abatement. There is some precautionary saving and private abatement, which is due to the fact that the utility function features prudence. If the government does not conduct any environmental policy at all then the system will settle in a stochastic steady state which we label the Stochastic Unmanaged Market Economy (SUME). Very long-run simulations of the SUME model show that the system displays clear and often longlasting epochs during which it fluctuates in the vicinity of either the low-welfare or high-welfare deterministic steady state. This is a clear demonstration of the reversible hysteresis that is a feature of the nonlinear model. Whilst the fluctuations in the economic variables are quite small (both within and between epochs), the variability of environmental quality is quite substantial. Private abatement activities are larger during a low-welfare epoch but they are not high enough to force the system back to the high-welfare basin of attraction.

In the second part of Sect. 4 we compute the stochastic (first-best) social optimum (SSO) that is chosen by a dynamically consistent social planner operating under the same degree of uncertainty as the public about future environmental quality. Such a planner computes state-dependent policy functions for private and public abatement, consumption by young and old, the future capital intensity, and the deterministic part of future environmental quality. Evaluated for the average capital intensity, the policy function for public abatement is strongly decreasing in pre-existing environmental quality whilst the one for private abatement displays the opposite pattern. This seemingly paradoxical result is explained by our maintained assumption that public abatement is more efficient than private abatement. Since the social planner operates in a stochastic environment the SSO constitutes a stochastic process for all key variables. To characterize the key features of this process we compute probability density functions for public and private abatement, the capital intensity, and environmental quality. Just as in the deterministic case the social planner eliminates the low-quality equilibrium by its policies, i.e. the PDF of environmental quality is 
centered tightly around the high-quality state of the environment. The comparison of the PDFs for environmental quality under the SUME and SSO reveals that the former is bimodal and the latter is unimodal. The PDF for expected lifetime utility at birth shows a similar pattern. In addition, in terms of lifetime utility there is a huge degree of inequality between lucky and unlucky generations. Behind the veil of ignorance individuals are vastly better off in a world fine-tuned by a social planner than under the unmanaged economy.

In the final part of Sect. 4 we investigate whether and to what extent a simple linear feedback policy rule for public abatement can improve welfare for current and future generations. The particular policy rule we consider stipulates that public abatement is a downward sloping linear function of the pre-existing environmental quality. To parameterize this function we fit a straight line though the relevant part of the SSO policy function evaluated at the average capital intensity. This rule obviously falls short of the first-best scenario, both because it is linear and because it does not address any issues other than public abatement by its very design. Surprisingly, however, the linear feedback policy rule does quite well. Compared to the unmanaged market outcome, the probability of environmental catastrophes is reduced sharply under the rule (but not eliminated altogether). This suggests that a simple constitutional rule for public abatement (binding the hands of future opportunistic politicians) may have some attractive features.

In Sect. 5 we conduct a robustness exercise in which we consider a number of parameter variations. In the interest of space we focus on the stationary distribution of environmental quality and show how it is affected by parameter changes in the market outcome and the planning solution.

Finally, in Sect. 6 we offer a brief summary of the main results and offer some thoughts on future work. An on-line Supplementary Material document contains a number of appendices presenting technical details.

\subsection{Relationship with the Existing Literature}

Our paper contributes to an ongoing literature on the interactions between the aggregate economy and the environment. One of the earliest contributions to that literature is the paper by John and Pecchenino (1994). They employ a deterministic two-period overlapping-generations model and assume that the environmental state equation features a linear regeneration function thus precluding tipping points. In terms of the principles mentioned above, only (P1) is addressed. Environmental quality is modeled as a pure public good but they abstract from the free-rider problem within a generation by assuming that a benevolent government sets taxes on the young and provides the right amount of environmental quality when these agents are old in the next period and derive utility from it.

Prieur (2009) generalizes the John-Pecchenino model by assuming that the environmental regeneration function is hump-shaped and becomes zero beyond a certain critical level of the pollution stock. As a result his model features a tipping point and gives rise to multiple equilibria. Hence both principles (P1) and (P2) are addressed. 
The young agent engages in private abatement and takes into account only what his/her green investment does to environmental quality when old. The public good nature of abatement is thus again ignored.

The nonlinear ecological dynamics described by Scheffer et al. (2001) is often referred to as Shallow-Lake Dynamics (SLD hereafter). For overviews of the SLD approach, see Muradian (2001), Mäler et al. (2003) and Brock and Starrett (2003). For economic applications of SLD, see Heijdra and Heijnen $(2013,2014)$ and the references therein.

In a number of papers Tsur and Zemel (1996, 1998, 2006) introduce a specific type of uncertainty into the environmental model, namely event uncertainty. In their approach there is a non-zero probability of an environmental disaster occurring at any time. Since this probability depends positively on the pollution stock, the social planner will take this mechanism into account when formulating an optimal environmental policy. The Tsur-Zemel papers have triggered a large and ongoing literature with prominent contributions by Polasky et al. (2011), Lemoine and Traeger (2014), van der Ploeg (2014), and van der Ploeg and de Zeeuw (2016, 2018). In this literature principles (P2) and (P3) are dealt with but (P1) is ignored. Heijnen and Dam (2019) adds (P4) but treats (P2) and (P3) in a parsimonious manner only. We view our modeling approach as being complementary to the one proposed by Tsur and Zemel. Indeed, like them we find that the probability of a catastrophic shift gets larger the closer environmental quality is to the tipping point. Our approach is slightly more general, however, in that we introduce a generational friction (by modeling disconnected generations) which replaces the infinitely-lived representative- agent framework that is often appealed to in this literature.

Although it is completely different in focus, the paper that comes closest to ours is Grass et al. (2015). They study a stochastic optimal control problem of the shallow-lake type in which the state equation for the pollution stock is continuously hit by random shocks. A social planner controls the usage of fertilizers and balances the conflicting interests of farmers (who indirectly benefit from pollution) and tourists (who are harmed by pollution). Depending on the noise intensity the optimal policy gives rise to a unimodal or bimodal probability density function for environmental quality. Whereas our benchmark model always yields a unimodal distribution of environmental quality, the analysis of Grass et al. (2015) suggests that this conclusion is dependent on both the functional form of the abatement technology and the parameterization of the model. The latter dependency is also demonstrated for our model in Sect. 5.

\subsection{Contributions}

Our paper intends to make the following contributions to the literature. First, in Sect. 2 we place overlapping generations of finitely-lived individuals at the center of the analysis. A social planner who respects the functional form of individual preferences and acts in a dynamically consistent manner is shown to formulate a social welfare function that features a 'within-period' social felicity function that depends on both the social and individual discount parameter. (Section 5 demonstrates the 
importance of recognizing this parameter interaction.) In the social planning exercise the planner implicitly 'chains together' the interests of current and future disconnected generations.

Second, in Sect. 3 we generalize the earlier deterministic contributions by John and Pecchenino (1994) and Prieur (2009) by (a) explicitly allowing for the free-rider problem (and demonstrating its importance in Sect. 5), and (b) by recognizing a weak 'warm-glow' mechanism by which individuals themselves contribute a little to environmental quality because it makes them feel good to do so.

Third, in Sect. 4 we formulate and study the stochastic theoretical-numerical version of our model. Compared to existing calibrated dynamic programming models, such as Cai et al. (2013) and Lemoine and Traeger (2014), our model is highly compact. This property makes the model ideally suited to identify the qualitative and quantitative importance of some of the key structural mechanism that are at work in it. For example, both private and social discount factors are shown to be crucial parameters affecting the shape of the optimal policy response of the social planner.

Fourth, in Sect. 5 we demonstrate the model's robustness and versatility. Despite its simplicity there is a rich array of patterns that are possible.

\section{A Deterministic Model}

In this section we develop and analyze a deterministic version of our overlappinggenerations model featuring two-period lived individuals who voluntarily engage in moderate amounts of private abatement, in part because such activities gives them a 'warm glow'. This approach was pioneered by Andreoni $(1989,1990)$ and is applied to the environment here. Environmental quality is negatively affected by the output produced in the economy, but both private and public abatement can be used to clean up the environmental mess created by human activities.

\subsection{Consumers}

Each period a large cohort of size $L$ of identical individuals is born. ${ }^{1}$ Each agent lives for two periods, works full-time during the first period of life (termed "youth") and is retired in the second period ("old age"). Lifetime utility of individual $i$ born at time $t$ is given by:

$$
\Lambda_{t}^{y, i} \equiv U\left(c_{t}^{y, i}\right)+\chi V\left(m_{t}^{i}\right)+\beta\left[U\left(c_{t+1}^{o, i}\right)+\zeta W\left(Q_{t+1}\right)\right],
$$

where $c_{t}^{y, i}$ and $c_{t+1}^{o, i}$ are, respectively, consumption during youth and old age, $m_{t}^{i}$ represents private environmental abatement activities ( $\chi$ is the 'warm-glow' parameter such that $\chi>0$ ), $Q_{t+1}$ is the quality of the environment during old age (a nonexcludable and non-rival public good, with $\zeta>0)$, and $\beta \equiv 1 /(1+\rho)$ is the discount

\footnotetext{
1 We follow John and Pecchenino (1994) by assuming that the population is constant (and equal to $2 L$ ).
} 
factor where $\rho>0$ is the pure rate of time preference. The felicity functions exhibit the usual properties, i.e. $U^{\prime}(x)>0, \lim _{x \rightarrow 0} U^{\prime}(x)=+\infty, U^{\prime \prime}(x)<0, V^{\prime}(x)>0$, $\lim _{x \rightarrow 0} V^{\prime}(x)=+\infty, V^{\prime \prime}(x)<0, W^{\prime}(x)>0, \lim _{x \rightarrow 0} W^{\prime}(x)=+\infty$, and $W^{\prime \prime}(x)<0$. Individuals have no bequest motive and, therefore, attach no utility to savings that remain after they die. Note that, in contrast to John and Pecchenino (1994) and Prieur (2009), we assume that the agent voluntarily engages in activities which are aimed at improving environmental quality and recognizes his/her own (small) effect on total abatement. ${ }^{2}$

The agent's budget identities for youth and old age are given by:

$$
\begin{gathered}
c_{t}^{y, i}+s_{t}^{i}+m_{t}^{i}=w_{t}-\tau_{t}, \\
c_{t+1}^{o, i}=\left(1+r_{t+1}\right) s_{t}^{i},
\end{gathered}
$$

where $w_{t}$ is the wage rate, $r_{t}$ is the interest rate, $s_{t}^{i}$ denotes the level of savings, and $\tau_{t}$ is the lump-sum tax charged by the government during youth. For reasons of analytical and computational convenience we abstract from taxation of old-age individuals. Agents are blessed with perfect foresight regarding all future variables. The transition equation for environmental quality takes the following form:

$$
Q_{t+1}=H\left(Q_{t}\right)-D_{t},
$$

where $H\left(Q_{t}\right)$ is an increasing function capturing the regenerative capacity of the environment $\left(H^{\prime}\left(Q_{t}\right)>0\right)$, and $D_{t}$ is the pollution flow resulting from economic activities. Throughout the paper we assume that the pollution flow is proportional to aggregate output produced in the economy (denoted by $Y_{t}$ ):

$$
D_{t}=\xi Y_{t} e^{-\gamma M_{t}-\eta G_{t}}, \quad \xi>0 .
$$

In Eq. (5), $G_{t}$ is public abatement, $M_{t} \equiv \sum_{i=1}^{L} m_{t}^{i}$ is total private abatement, and $\gamma$ and $\eta$ are constant positive parameters. By entering these abatement activities exponentially we incorporate the notion of convex adjustment costs, i.e. $\quad \partial D_{t} / \partial G_{t}=-\eta D_{t}<0, \quad \partial^{2} D_{t} / \partial G_{t}^{2}=\eta^{2} D_{t}>0, \quad \partial D_{t} / \partial M_{t}=-\gamma D_{t}<0$, $\partial^{2} D_{t} / \partial M_{t}^{2}=\gamma^{2} D_{t}>0$. We assume that the government is more efficient at abatement than private individuals are, i.e. $\eta>\gamma>0$. Since output is strictly positive the flow of dirt is guaranteed to be positive also, i.e. $D_{t}>0$. Two prototypical specifications for the regeneration function, $H\left(Q_{t}\right)$, are formulated and discussed below.

Agent $i$ chooses $c_{t}^{y, i}, c_{t+1}^{o, i}, s_{t}^{i}$, and $m_{t}^{i}$ in order to maximize expected lifetime utility (1) subject to the budget identities (2)-(3) and the environmental transition function (4). The individual takes as given factor prices, taxes, aggregate output, as well

\footnotetext{
${ }^{2}$ Both studies abstract from the free-rider problem within a generation. John and Pecchenino (1994, p. 1396) provide an interpretation for this assumption and relate it to Lindahl pricing (which they leave unmodelled). See Sect. 5 on the implications of free-riding for the stationary distribution of environmental quality in a stochastic world.
} 
as the abatement expenditures by other individuals, $M_{t}^{i} \equiv \sum_{j \neq i}^{L} m_{t}^{j}$, and the government, $G_{t}$. We define $Z_{t}$ as:

$$
Z_{t} \equiv \xi Y_{t} e^{-\gamma M_{t}^{\top i}-\eta G_{t}}
$$

note that $D_{t}=Z_{t} e^{-\gamma m_{t}^{i}}$, and find that the key first-order conditions are:

$$
\begin{gathered}
U^{\prime}\left(c_{t}^{y, i}\right)=\beta\left(1+r_{t+1}\right) U^{\prime}\left(c_{t+1}^{o, i}\right), \\
U^{\prime}\left(c_{t}^{y, i}\right)=\chi V^{\prime}\left(m_{t}^{i}\right)+\beta \gamma \zeta Z_{t} e^{-\gamma m_{t}^{i}} W^{\prime}\left(H\left(Q_{t}\right)-Z_{t} e^{-\gamma m_{t}^{i}}\right) .
\end{gathered}
$$

The optimal savings decision is implicitly characterized by the consumption Euler equation in (7). It ensures that the marginal rate of substitution between future and current consumption is equated to the intertemporal price of future consumption. The optimal abatement choice is characterized by (8). Here the trade-off is between giving up some current consumption (left-hand side) in order to experience a warm glow (first term on the right-hand side) and to obtain a slight gain in future environmental utility (second term).

In the remainder of this paper we assume that the three felicity functions featuring in lifetime utility are logarithmic, i.e. $U(x)=V(x)=W(x)=\ln x$. Since all agents in a given cohort are identical, it follows that they make the same choices, i.e. $c_{t}^{y, i}=c_{t}^{y}$, $s_{t}^{i}=s_{t}, m_{t}^{i}=m_{t}$, and $c_{t+1}^{o, i}=c_{t+1}^{o}$ for all $i$. The optimal choices for $c_{t}^{y}, m_{t}$, and $c_{t+1}^{o}$ are characterized by:

$$
\begin{gathered}
\frac{c_{t+1}^{o}}{c_{t}^{y}}=\beta\left(1+r_{t+1}\right), \\
\frac{\chi}{m_{t}}+\frac{\beta \gamma \zeta e^{-\gamma L m_{t}} D_{t}^{g}}{H\left(Q_{t}\right)-e^{-\gamma L m_{t}} D_{t}^{g}}=\frac{1}{c_{t}^{y}}, \\
c_{t}^{y}+m_{t}+\frac{c_{t+1}^{o}}{1+r_{t+1}}=w_{t}-\tau_{t}, \\
D_{t}^{g}=\xi L y_{t} e^{-\eta L g_{t}},
\end{gathered}
$$

where $y_{t} \equiv Y_{t} / L$ and $g_{t} \equiv G_{t} / L$ are, respectively, output and public abatement per worker, and $D_{t}^{g}$ is the dirt flow that would result in the absence of private abatement (the so-called gross dirt flow). Ceteris paribus $w_{t}-\tau_{t}, r_{t+1}, Q_{t}$, and $D_{t}^{g}$, the optimal choices made by the individual can be explained with the aid of Fig. 1. In the top panel the curve labeled $\mathrm{PA}_{0}$ represents Eq. (10) and states the optimal level of private abatement for different levels of youth consumption. The curve labeled $\mathrm{HBC}_{0}$ is the household budget constraint. It is obtained by substituting (9) into (11):

$$
m_{t}+(1+\beta) c_{t}^{y}=w_{t}-\tau_{t} .
$$


Fig. 1 Privately optimal consumption and private abatament

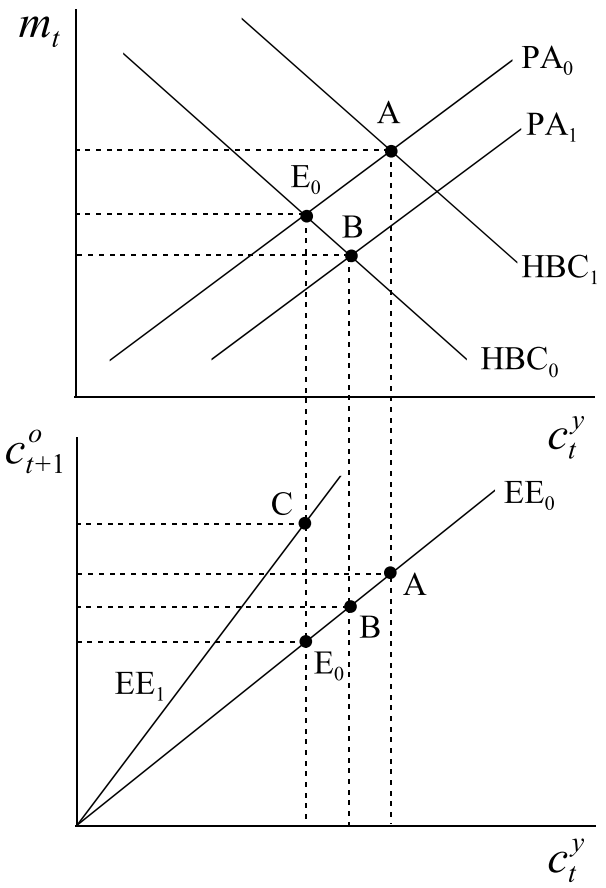

Because (a) the logarithmic felicity functions imply a unitary intertemporal substitution elasticity and (b) agents do not receive any wage income or pay taxes during old-age, the budget constraint is independent of the future real interest rate. The optimum choices for $m_{t}$ and $c_{t}^{y}$ are located at point $\mathrm{E}_{0}$ in the top panel, and can be written as $m_{t}=\mathbf{m}\left(w_{t}-\tau_{t}, Q_{t}, D_{t}^{g}\right)$ and $c_{t}^{y}=\mathbf{c}^{y}\left(w_{t}-\tau_{t}, Q_{t}, D_{t}^{g}\right)$. The implied savings function is written as $s_{t}=\mathbf{s}\left(w_{t}-\tau_{t}, Q_{t}, D_{t}^{g}\right)$. In the bottom panel of Fig. 1 $\mathrm{EE}_{0}$ depicts the consumption Euler equation (9). For future reference we write $c_{t+1}^{o}=\beta\left(1+r_{t+1}\right) \mathbf{c}^{y}\left(w_{t}-\tau_{t}, Q_{t}, D_{t}^{g}\right)$.

The comparative static effects of the various determinants of $m_{t}, c_{t}^{y}$, and $s_{t}$ can be illustrated with the aid of Fig. 1. First, an increase in $w_{t}$ (or decrease in $\tau_{t}$ ) shifts the budget equation from $\mathrm{HBC}_{0}$ to $\mathrm{HBC}_{1}$ so that the new private optimum occurs at point A. It follows that $m_{t}, c_{t}^{y}$, and $c_{t+1}^{o} \quad$ are normal goods, i.e. $0<\mathbf{m}_{w} \equiv \partial \mathbf{m}\left(w_{t}-\tau_{t}, Q_{t}, D_{t}^{g}\right) / \partial\left(w_{t}-\tau_{t}\right)<1$, $0<\partial \mathbf{c}^{y}\left(w_{t}-\tau_{t}, Q_{t}, D_{t}^{g}\right) / \partial\left(w_{t}-\tau_{t}\right)<1$, and $\partial c_{t+1}^{o} / \partial\left(w_{t}-\tau_{t}\right)>0 \quad$. Saving also increases, i.e. $0<\mathbf{s}_{w} \equiv \partial \mathbf{s}\left(w_{t}-\tau_{t}, Q_{t}, D_{t}^{g}\right) / \partial\left(w_{t}-\tau_{t}\right)<1$. Second, an increase in the future interest rate has no effect on the optimal choices for $m_{t}, c_{t}^{y}$, and $s_{t}$ but it leads to an increase in $c_{t+1}^{o}$. In the bottom panel of Fig. 1 the Euler equation rotates from $\mathrm{EE}_{0}$ to $\mathrm{EE}_{1}$ and the private optimum shifts from point $\mathrm{E}_{0}$ to C. Third, an increase in $Q_{t}$ and a decrease in $D_{t}^{g}$ both lead to a downward shift in the private abatement curve, say from $\mathrm{PA}_{0}$ to $\mathrm{PA}_{1}$ in the top panel of Fig. 1. The optimum shifts from $\mathrm{E}_{0}$ to $\mathrm{B}$ in both panels, and it follows that $\mathbf{m}_{Q} \equiv \partial \mathbf{m}\left(w_{t}-\tau_{t}, Q_{t}, D_{t}^{g}\right) / \partial Q_{t}<0, \mathbf{m}_{D} \equiv \partial \mathbf{m}\left(w_{t}-\tau_{t}, Q_{t}, D_{t}^{g}\right) / \partial D_{t}^{g}>0$, 
$\partial \mathbf{c}^{y}\left(w_{t}-\tau_{t}, Q_{t}, D_{t}^{g}\right) / \partial Q_{t}>0, \partial \mathbf{c}^{y}\left(w_{t}-\tau_{t}, Q_{t}, D_{t}^{g}\right) / \partial D_{t}^{g}<0, \mathbf{s}_{Q} \equiv \partial \mathbf{s}\left(w_{t}-\tau_{t}, Q_{t}, D_{t}^{g}\right) / \partial Q_{t}>0$, $\mathbf{s}_{D} \equiv \partial \mathbf{s}\left(w_{t}-\tau_{t}, Q_{t}, D_{t}^{g}\right) / \partial D_{t}^{g}<0, \partial c_{t+1}^{o} / \partial Q_{t}>0$ and $\partial c_{t+1}^{o} / \partial D_{t}^{g}<0$.

\subsection{Firms}

The firm sector is perfectly competitive and operates under constant returns to scale. The representative firm hires capital $K_{t}$ and labour $N_{t}$ in order to produce homogeneous output $Y_{t}$. For simplicity the technology available to the firm is of the Cobb-Douglas form:

$$
Y_{t}=\Omega K_{t}^{\alpha} N_{t}^{1-\alpha}, \quad 0<\alpha<1,
$$

where $\alpha$ is the efficiency parameter of capital and $\Omega$ is the aggregate level of technology in the economy. The firm maximizes profit, $\pi_{t}=Y_{t}-w_{t} N_{t}-\left(r_{t}+\delta\right) K_{t}$, and its factor demands are given by the following marginal productivity conditions:

$$
\begin{aligned}
& w_{t}=(1-\alpha) \Omega k_{t}^{\alpha}, \\
& r_{t}+\delta=\alpha \Omega k_{t}^{\alpha-1},
\end{aligned}
$$

where $k_{t} \equiv K_{t} / L$ is the capital intensity, $\delta>0$ is the depreciation rate, and we have incorporated labour market equilibrium, $N_{t}=L$. Output per worker is thus given by:

$$
y_{t}=f\left(k_{t}\right) \equiv \Omega k_{t}^{\alpha},
$$

where $y_{t} \equiv Y_{t} / L$.

\subsection{Other Model Features}

The economy-wide resource constraint per worker (used in the social planning problem below) can be written as:

$$
y_{t}+(1-\delta) k_{t}=c_{t}^{y}+c_{t}^{o}+m_{t}+g_{t}+k_{t+1},
$$

where $g_{t} \equiv G_{t} / L$ is public abatement spending per worker. Total available resources, consisting of output and the undepreciated part of the capital stock, are spent on consumption (by young and old individuals), on abatement (by young agents and the government), and on the future stock of capital. In the unmanaged market economy total saving by the young determines the future capital stock, i.e. $L s_{t}=K_{t+1}$ or:

$$
k_{t+1}=s_{t} .
$$

In the absence of public debt, the government budget constraint per worker can be written as: 
Table 1 The deterministic environmental overlapping-generations model

\begin{tabular}{ll}
\hline$k_{t+1}=\mathbf{s}\left(w_{t}-g_{t}, Q_{t}, D_{t}^{g}\right)$, & $(\mathrm{T} 1.1)$ \\
$Q_{t+1}=H\left(Q_{t}\right)-e^{-\gamma L \mathbf{m}\left(w_{t}-g_{t}, Q_{t}, D_{t}^{g}\right)} D_{t}^{g}$ & $(\mathrm{~T} 1.2)$ \\
$y_{t}=\Omega k_{t}^{\alpha}$ & $(\mathrm{T} 1.3)$ \\
$w_{t}=(1-\alpha) y_{t}$ & $(\mathrm{~T} 1.4)$ \\
$D_{t}^{g}=\xi L y_{t} e^{-\eta L g_{t}}$ & $(\mathrm{~T} 1.5)$ \\
Variables & Parameters \\
$k_{t} \quad$ Capital intensity & $\Omega$ Productivity parameter $(\Omega>0)$ \\
$Q_{t} \quad$ Environmental quality & $\alpha$ Efficiency parameter of capital $(0<\alpha<1)$ \\
$y_{t}$ Output per worker & $\gamma$ Private abatement parameter $(\gamma>0)$ \\
$g_{t} \quad$ Public abatement per worker & $\eta$ Public abatement parameter $(\eta>\gamma)$ \\
$w_{t} \quad$ Wage rate & $\xi$ Output dirt parameter $(\xi>0)$ \\
$D_{t}^{g} \quad$ Gross dirt flow & $L$ Number of workers \\
\hline
\end{tabular}

$$
g_{t}=\tau_{t}^{y}
$$

The policy maker uses public abatement as its environmental instrument and balances the budget by choice of the lump-sum tax on the young.

In the unmanaged market economy households maximize lifetime utility subject to a lifetime budget constraint, taking as given factor prices, environmental quality, and public abatement. Firms maximize profit by hiring factors of production from the households. The government exogenously sets the level of public abatement and uses taxes on the young to finance it. For future reference the deterministic overlapping-generations model developed in this section has been summarized in Table 1. Equation (T1.1) is obtained by substituting the savings function (with (20) imposed), $\mathbf{s}\left(w_{t}-g_{t}, Q_{t}, D_{t}^{g}\right)$, into the capital accumulation equation (19). Equation (T1.2) is obtained by using (4)-(5) and (12), and substituting the private abatement function, $\mathbf{m}\left(w_{t}-g_{t}, Q_{t}, D_{t}^{g}\right)$. Equations (T1.3)-(T1.5) restate, respectively, (17), (15), and (12).

\section{Economic-Environmental Dynamics in a Deterministic World}

\subsection{Unmanaged Market Equilibrium}

Despite its highly stylized nature the model stated in Table 1 incorporates a rich array of interactions between the environment and the economic process. Indeed, the fundamental system of difference equations for the capital intensity and environmental quality is fully characterized by:

$$
\begin{gathered}
k_{t+1}=\mathbf{s}\left((1-\alpha) \Omega k_{t}^{\alpha}-g_{t}, Q_{t}, D_{t}^{g}\right), \\
Q_{t+1}=H\left(Q_{t}\right)-e^{-\gamma L \mathbf{m}\left((1-\alpha) \Omega k_{t}^{\alpha}-g_{t}, Q_{t}, D_{t}^{g}\right)} D_{t}^{g},
\end{gathered}
$$




$$
D_{t}^{g}=\xi L \Omega k_{t}^{\alpha} e^{-\eta L g_{t}} .
$$

Because young individuals care for the environmental quality they will enjoy during old-age $\left(\mathbf{s}_{Q}>0\right)$, the dynamics of the capital intensity is affected by the current state of the environment, $Q_{t}$. Furthermore, the dynamics of environmental quality is affected by the current capital intensity, $k_{t}$, both because of its effect on current output and wages, and because young agents increase the level of private abatement if the gross pollution flow increases $\left(\mathbf{m}_{D}>0\right)$.

We assume that public abatement is equal to zero and that the system features a steady state equilibrium denoted by $\left(k^{*}, Q^{*}\right)$. Local dynamic around the steady state can then - at least in principle — be studied with the aid of the linearized system:

$$
\left[\begin{array}{c}
k_{t+1}-k^{*} \\
Q_{t+1}-Q^{*}
\end{array}\right]=\Delta\left[\begin{array}{c}
k_{t}-k^{*} \\
Q_{t}-Q^{*}
\end{array}\right]
$$

where the Jacobian matrix is defined as:

$$
\Delta \equiv\left[\begin{array}{cc}
{\left[(1-\alpha) \mathbf{s}_{w}+\xi L \mathbf{s}_{D}\right]\left(r^{*}+\delta\right)} & \mathbf{s}_{Q} \\
{\left[\gamma(1-\alpha) \mathbf{m}_{w}+\gamma \xi L \mathbf{m}_{D}-1 /\left(L f\left(k^{*}\right)\right)\right] L D^{*}\left(r^{*}+\delta\right)} & H^{\prime}\left(Q^{*}\right)+\gamma L D^{*} \mathbf{m}_{Q}
\end{array}\right],
$$

and where $\mathbf{s}_{w}, \mathbf{s}_{Q}, \mathbf{s}_{D}, \mathbf{m}_{w}, \mathbf{m}_{Q}$, and $\mathbf{m}_{D}$ denote the partial derivatives of the savings and abatement functions with respect to the argument in the subscript. We recall from the preceding discussion that $0<\mathbf{s}_{w}, \mathbf{m}_{w}<1, \mathbf{s}_{Q}>0, \mathbf{s}_{D}<0, \mathbf{m}_{Q}<0$, and $\mathbf{m}_{D}>0$. Since both $k_{t}$ and $Q_{t}$ are predetermined variables, stability requires the characteristic roots of $\Delta$ to lie inside the unit circle.

As is clear from the structure of the Jacobian matrix in (25) the model is too complicated for it to yield clear-cut analytical results. For that reason we adopt a plausible parameterization of the model and use it to numerically study the interaction between the environment and the economy in the remainder of this paper. Although it is not difficult to come up with plausible values for the purely economic parameters (such as $\alpha, \beta$ and $\delta$ ) it is much harder to assign numbers to the structural parameters characterizing the environmental effects in the model $(\gamma, \zeta, \eta, \xi$, and $\chi)$. We document our parameterization approach in detail in Supplementary Material (Online Appendix A). Essentially we formulate targets relating to economic and environmental variables that must be met in the unmanaged market economy.

Table 2 provides an overview of the structural parameters of the model. Each period is assumed to last for 30 years and there are one hundred individuals in the economy $(L=100)$. The discount factor $\beta$ is based on an annual rate of pure time preference $\left(\rho_{a}\right)$ of four percent. The efficiency parameter of capital in the production function is equal to $\alpha=0.3$. The constant in the production function is set such that the target level of output equals unity. Furthermore, the capital depreciation rate is chosen such that the target (annual) interest rate of 2.5 percent is attained.

In order to prepare for things to come, we first visualize some aspects of the parameterized steady-state market equilibrium of the unmanaged economy conditional on the steady-state level of environmental quality $\hat{Q}$ (and without public abatement, $g_{t}=0$ ). The advantage of doing so is that it allows us to derive insights into the basic 
Table 2 Structural parameters

\begin{tabular}{llll}
\hline \multicolumn{2}{l}{ Economic parameters } & & \\
$\beta$ & Discount factor & & 0.3083 \\
$L$ & Young cohort size & & 100.0000 \\
$\rho_{a}$ & Annual time preference (percent) & & 4.0000 \\
$\alpha$ & Capital share parameter & & 0.3000 \\
$\Omega$ & Production function constant & $\mathrm{c}$ & 1.7190 \\
$\delta_{a}$ & Annual capital depreciation rate (percent) & $\mathrm{c}$ & 4.2468 \\
$\delta$ & Capital depreciation factor & $\mathrm{c}$ & 0.7280 \\
Environmental parameters & & \\
$\chi$ & Taste parameter for private abatement & $\mathrm{c}$ & $4.8584 \times 10^{-3}$ \\
$\zeta$ & Taste parameter for future environmental quality & & 25.0000 \\
$\gamma$ & Environmental dirt-private-abatement parameter & $\mathrm{c}$ & $7.5807 \times 10^{-2}$ \\
$\eta$ & Environmental dirt-public-abatement parameter & $\mathrm{c}$ & $8.4230 \times 10^{-2}$ \\
$\xi$ & Environmental dirt-output parameter & $\mathrm{c}$ & $2.3190 \times 10^{-3}$ \\
$\theta_{a}$ & Annual rate of environmental regeneration (percent) & & 2.0000 \\
$\theta$ & Environmental regeneration factor & & 0.4545 \\
$\bar{Q}$ & Maximum environmental quality & & 3.0000 \\
\hline
\end{tabular}

See Supplementary Material (Online Appendix A) for details on the parameterization approach. The parameters labeled ' $c$ ' are calibrated as is explained in the appendix. The remaining parameters are postulated a priori. The values for $\delta, \theta$, and $\beta \equiv 1 /(1+\rho)$ follow from, respectively, $\delta_{a}, \theta_{a}$, and $\rho_{a}$, by noting that each model period represents 30 years

mechanisms at work in the unmanaged economy without having to postulate a specific functional form for the regeneration function $H\left(Q_{t}\right)$. The system characterizing the conditional steady state of the unmanaged market equilibrium is given by:

$$
\begin{gathered}
\hat{c}^{o}=\beta(1+\hat{r}) \hat{c}^{y}, \\
\frac{1}{\hat{c}^{y}}=\frac{\chi}{\hat{m}}+\frac{\beta \gamma \zeta \hat{D}}{\hat{Q}}, \\
\hat{w}=\hat{c}^{y}+\hat{k}+\hat{m}, \\
\hat{c}^{o}=(1+\hat{r}) \hat{k}, \\
\hat{r}=\alpha \Omega \hat{k}^{\alpha-1}-\delta, \\
\hat{w}=(1-\alpha) \Omega \hat{k}^{\alpha}, \\
\hat{D}=\xi L \Omega \hat{k}^{\alpha} e^{-\gamma L \hat{m}},
\end{gathered}
$$


(a) Capital intensity $\hat{k}$

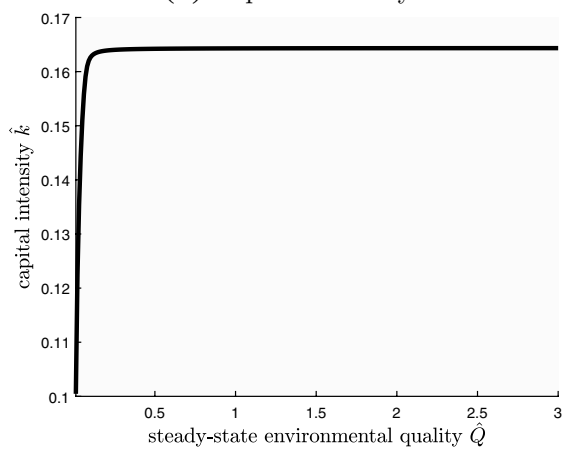

(c) Private abatement $\hat{m}$

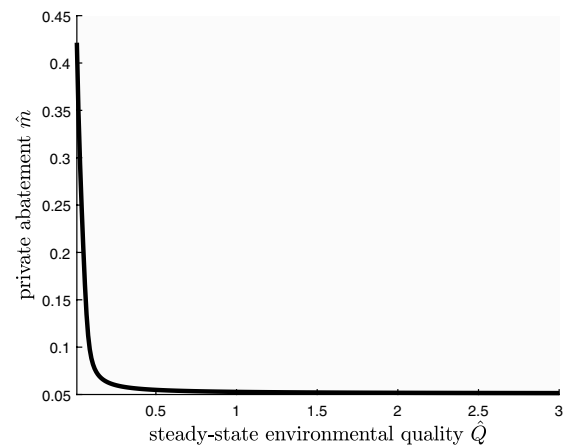

(e) Youth consumption $\hat{c}^{y}$

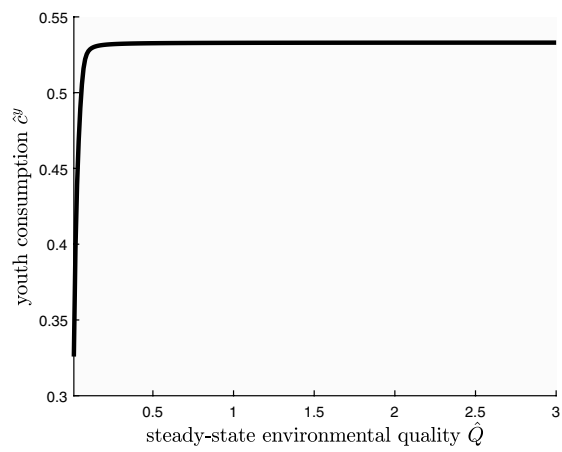

(b) Output $\hat{y}$



(d) Dirt flow $\hat{D}$

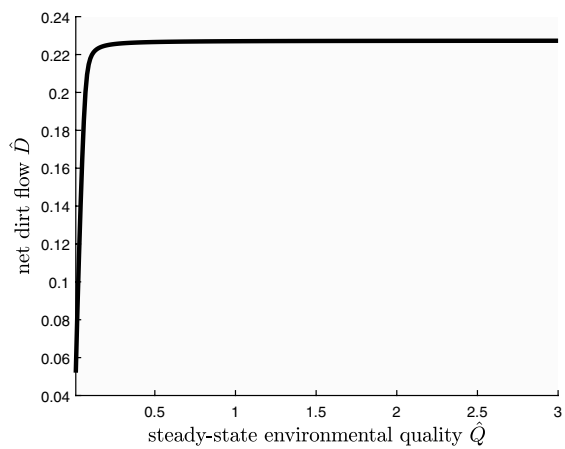

(f) Old-age consumption $\hat{c}^{o}$

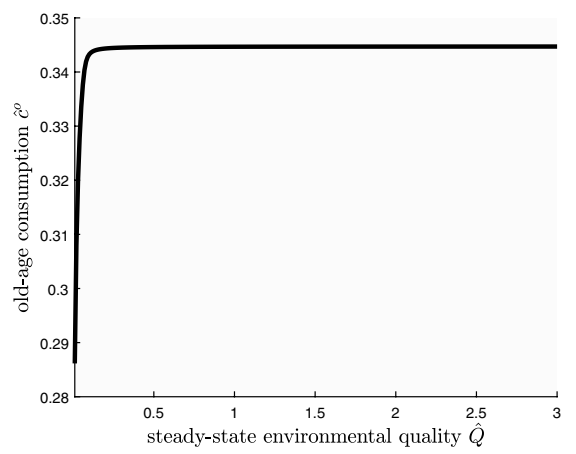

Fig. 2 The steady-state unmanaged economy conditional on environmental quality. Legend Steady-state environmental quality is such that $0 \leq \hat{Q} \leq \bar{Q}$. The values for $\hat{c}^{o}, \hat{c}^{y}, \hat{m}, \hat{k}$, and $\hat{D}$ are obtained by solving the system in (26)-(32) for all values of $\hat{Q}$ in the domain. Output satisfies $\hat{y}=\Omega \hat{k}^{\alpha}$. See also Numerical Result 1

where hats denote steady-state values and where the endogenous variables are $\hat{c}^{o}, \hat{c}^{y}$, $\hat{m}, \hat{k}, \hat{w}, \hat{r}$, and $\hat{D}$.

We assume that environmental quality lies in the interval $[0, \bar{Q}]$ with $Q_{t} \approx 0$ representing a situation comparable to Dante's Inferno whilst $Q_{t}=\bar{Q}$ can be seen as 
characterizing the pristine environment. In Fig. 2 we depict the conditional steady state for a number of key variables (noting that output per worker is given by $\left.\hat{y}=\Omega \hat{k}^{\alpha}\right)$. The main lesson to be learned from the figure is unambiguous. For all but extremely low values of steady-state environmental quality, $\hat{k}, \hat{y}, \hat{m}, \hat{c}^{y}$, and $\hat{c}^{o}$ are virtually independent of the value of $\hat{Q}$. Utility-maximizing individuals will only engage in a large amount of private abatement (and cut back their saving a lot to do so) if push comes to shove, i.e. if the environmental quality comes close to diabolical levels. For any other values of $\hat{Q}$, such individuals will conduct a modest amount of private abatement in order to satisfy their warm-glow motive for doing so.

Numerical Result 1 (Environmental quality and private choices) For the benchmark parameterization given in Table 2, it holds that for all but extremely low values of steady-state environmental quality $\hat{Q}$, the steady-state economic variables $(\hat{k}, \hat{y}$, $\hat{m}, \hat{c}^{y}$, and $\hat{c}^{o}$ ) are virtually independent of the value of $\hat{Q}$.

Whilst the Fig. 2 is useful to illustrate some mechanisms at work, it does not pin down which equilibrium will actually be attained. In order to determine the equilibrium in the unmanaged economy we must adopt a specific functional form for the environmental regeneration function $H\left(Q_{t}\right)$. In the next two subsections we will consider two prototypical regeneration functions, a linear one (giving rise to a unique steady-state equilibrium) and a nonlinear one (yielding multiple steady-state equilibria).

\subsubsection{Linear Environmental Dynamics}

In this subsection we assume that the environmental regeneration function is linear:

$$
H\left(Q_{t}\right) \equiv \theta \bar{Q}+(1-\theta) Q_{t},
$$

where $\bar{Q}>0$ is the maximum level of environmental quality (pristine nature), and $\theta$ is the adjustment parameter satisfying $0<\theta<1$. In our numerical simulations we assume that the annual rate of environmental regeneration $\left(\theta_{a}\right)$ is two percent (see Table 2), implying a relatively slow rate of adjustment in environmental quality (compared to the speed of adjustment in the economic process). By using (33) in (4) and imposing the steady state we find:

$$
\hat{Q}=\bar{Q}-\frac{1}{\theta} \hat{D}
$$

For a given steady-state flow of $\operatorname{dirt}(\hat{D})$, there exists a unique steady-state quality of the environment. The solid line in Fig. 3a illustrates the relationship between $\hat{Q}$ and $\hat{D}$ for the linear case. Similarly, the solid line in Fig. $3 b$ depicts the fundamental difference equation for environmental quality, holding constant the total flow of dirt.

The key features of the steady-state market equilibrium are reported in Table 3(a). Environmental quality $\hat{Q}$ is (calibrated to be) close to its pristine level $\bar{Q}$ and we refer to this equilibrium as the clean steady state $\left(\mathrm{ME}_{c}\right)$. Private abatement is positive but rather small. Indeed, it is calibrated to be a half percent of youth consumption in the 
(a) Linear $H\left(Q_{t}\right)$

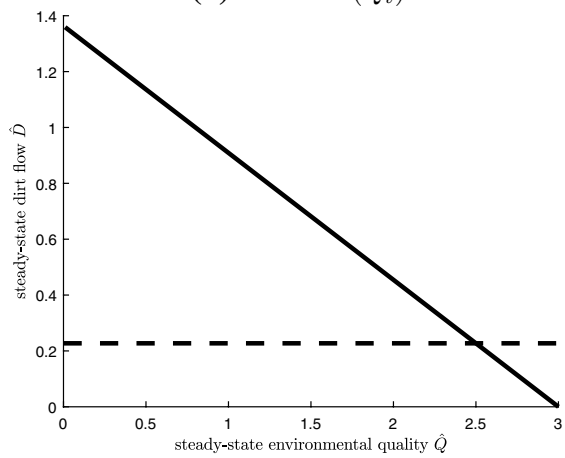

(c) Nonlinear $H\left(Q_{t}\right)$

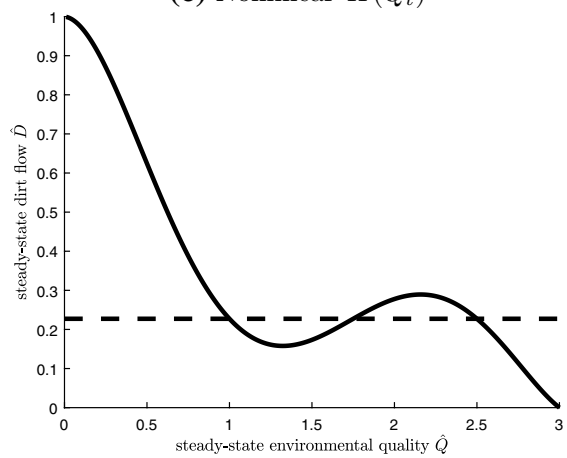

(b) Linear FDE for $Q_{t}$

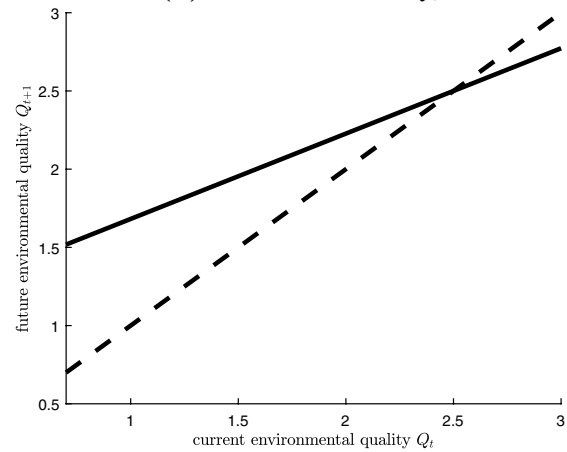

(d) Nonlinear FDE for $Q_{t}$

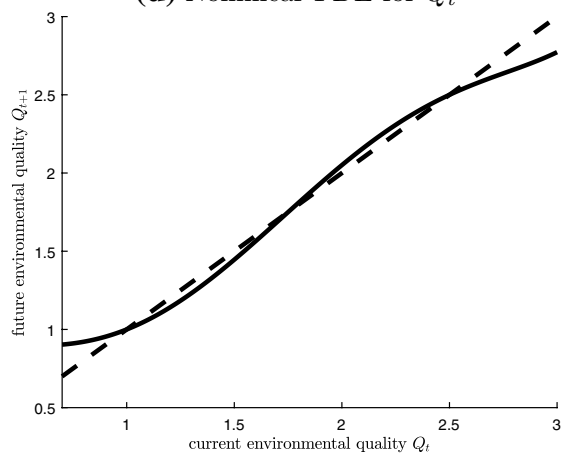

Fig. 3 Linear and non-linear $H(Q)$ functions. Note In panels (a, c) the solid lines depict the regeneration functions and the dashed lines visualize the steady-state dirt flow $\hat{D}=0.2273$ (see Fig. $2 \mathrm{~d}$ ). In the linear case the regeneration function is given by Eq. (33). The nonlinear case incorporates a quintic regeneration function as given in Eq. (35). In panels $(\mathbf{b}, \mathbf{d})$ the solid lines depict the fundamental difference equation whilst the dashed lines visualize the steady-state condition

clean steady state. The characteristic roots of the linearized system (see (24)) equal $\lambda_{1}=0.2999$ and $\lambda_{2}=0.5454$ implying that the system is stable and converges to the unique steady steady state from any feasible initial condition $\left(k_{0}, Q_{0}\right)$. In Fig. 4 we illustrate the adjustment paths for $k_{t}, Q_{t}, m_{t}$, and $D_{t}$ when the system faces the initial conditions $(0.1643,1.0005)$. At time $t=0$ capital and environmental quality are predetermined. Private abatement is higher than its long-run level whilst the dirt flow is slightly lower than its steady-state level.

\subsubsection{Non-linear Environmental Dynamics}

In recent years prominent ecologists have argued that ecosystems may exhibit catastrophic shifts in the vicinity of threshold points (Scheffer et al. 2001). Whilst such shifts are impossible when the regeneration function is linear (as in the previous subsection), they become possible when this function displays the right kind of 
Table 3 Allocation and welfare

\begin{tabular}{|c|c|c|c|c|c|}
\hline & & (a) & (b) & (c) & (d) \\
\hline & & $\mathrm{ME}_{c}$ & $\mathrm{ME}_{d}$ & $\mathrm{DSO}_{l}$ & $\mathrm{DSO}_{n}$ \\
\hline$\hat{Q}$ & $\begin{array}{l}\text { Environmental } \\
\text { quality }\end{array}$ & 2.5000 & 1.0005 & 2.7604 & 2.7570 \\
\hline$\hat{k}$ & Capital intensity & 0.1643 & 0.1643 & 0.0642 & 0.0642 \\
\hline$\hat{r}$ & Interest factor & 1.0976 & 1.0979 & 2.7986 & 2.7986 \\
\hline$\hat{r}^{a}$ & $\begin{array}{l}\text { Annual interest } \\
\text { rate (percent) }\end{array}$ & $2.5000 \%$ & $2.5005 \%$ & $4.5492 \%$ & $4.5492 \%$ \\
\hline$\hat{y}$ & Output per worker & 1.0000 & 0.9999 & 0.7541 & 0.7541 \\
\hline$\hat{w}$ & Wage rate & 0.7000 & 0.6999 & 0.5279 & 0.5279 \\
\hline$\hat{m}$ & Private abatement & $0.2665 \times 10^{-2}$ & $0.2786 \times 10^{-2}$ & $1.5780 \times 10^{-2}$ & $1.5826 \times 10^{-2}$ \\
\hline$\hat{c}^{y}$ & $\begin{array}{l}\text { Youth consump- } \\
\text { tion }\end{array}$ & 0.5330 & 0.5329 & 0.3248 & 0.3257 \\
\hline$\hat{c}^{o}$ & $\begin{array}{l}\text { Old-age con- } \\
\text { sumption }\end{array}$ & 0.3447 & 0.3447 & 0.3248 & 0.3257 \\
\hline$\hat{g}$ & Public abatement & 0.0000 & 0.0000 & 0.0420 & 0.0401 \\
\hline$\hat{D}$ & Net dirt flow & 0.2273 & 0.2270 & 0.1089 & 0.1106 \\
\hline$\hat{\Lambda}^{y}$ & Life-time utility & 6.0763 & -0.9826 & 6.3352 & 6.3294 \\
\hline
\end{tabular}

With a linear environmental regeneration function $H\left(Q_{t}\right)$ the unmanaged market economy settles in the unique steady state labeled $\mathrm{ME}_{c}$. If $H\left(Q_{t}\right)$ is nonlinear there is also a heavily polluted steady state for the unmanaged economy labeled $\mathrm{ME}_{d}$. $\mathrm{DSO}_{l}$ and $\mathrm{DSO}_{n}$ denote the deterministic first-best social optimum for, respectively, the linear and nonlinear regeneration function

non-linearity. In this subsection we study the dynamic behaviour of the unmanaged economy in the presence of tipping points.

To keep things simple we adopt the following quintic regeneration function:

$$
H\left(Q_{t}\right) \equiv \phi_{5} Q_{t}^{5}+\phi_{4} Q_{t}^{4}+\phi_{3} Q_{t}^{3}+\phi_{2} Q_{t}^{2}+\left(1+\phi_{1}\right) Q_{t}+\phi_{0},
$$

where the $\phi_{i}$ parameters are chosen such that the resulting fundamental difference equation for environmental quality is S-shaped and, for a given net dirt flow, features two stable steady states. ${ }^{3}$ See Fig. $3 d$. The regeneration function itself has been illustrated in Fig. 3c for different steady-state values of $Q$. The parameterization of $H\left(Q_{t}\right)$ is explained in detail in Supplementary Material (Online Appendix A).

\footnotetext{
3 In the literature on shallow lake dynamics a specific functional form of the regeneration function is typically employed which takes the following form:

$$
P_{t+1}=(1-\pi) P_{t}+\frac{P_{t}^{2}}{P_{t}^{2}+1}+D_{t}, \quad \frac{1}{2}<\pi<\frac{3 \sqrt{3}}{8},
$$

where $P_{t}$ is the pollution stock at time $t$ and $Q_{t} \equiv \bar{Q}-P_{t}$. This function is qualitatively similar to our quintic expression and we use the latter because it is easier to parameterize.
} 
(a) Capital intensity $k_{t}$

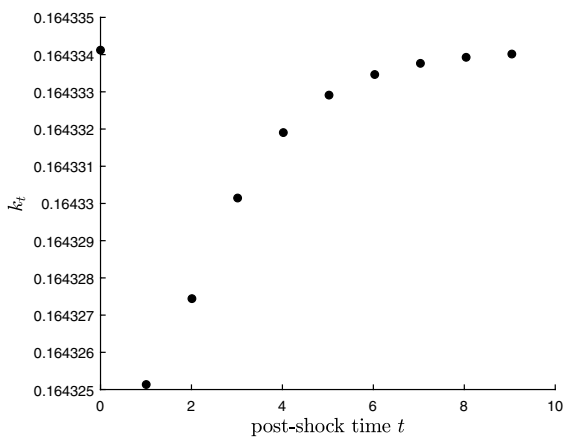

(c) Private abatement $m_{t}$

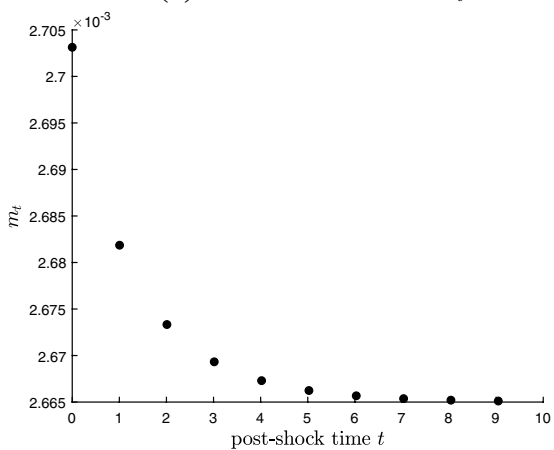

(e) Youth consumption $c_{t}^{y}$

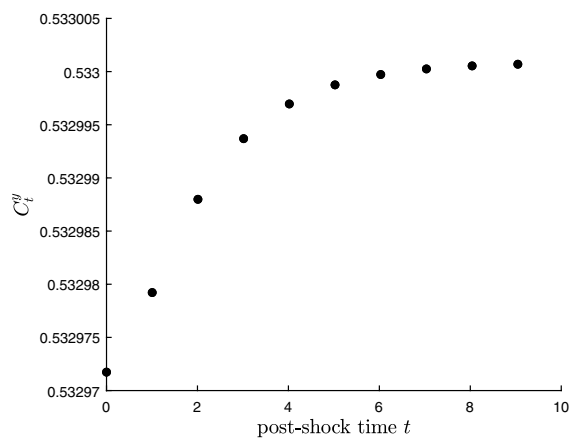

(b) Environmental quality $Q_{t}$

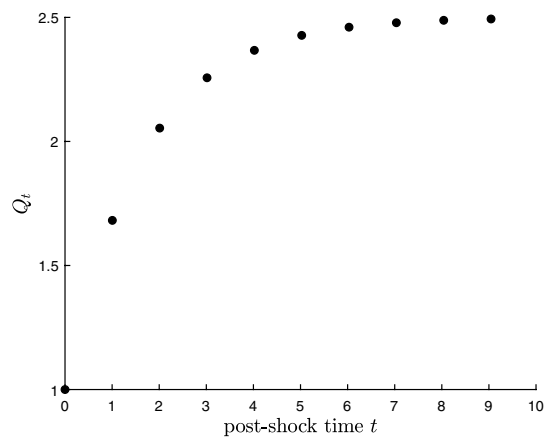

(d) Dirt flow $D_{t}$

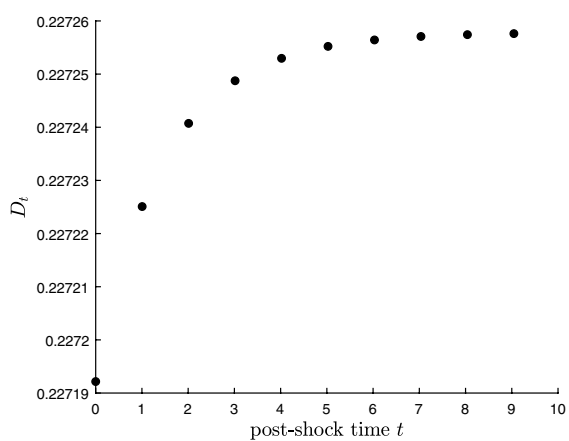

(f) Old-age consumption $c_{t}^{o}$

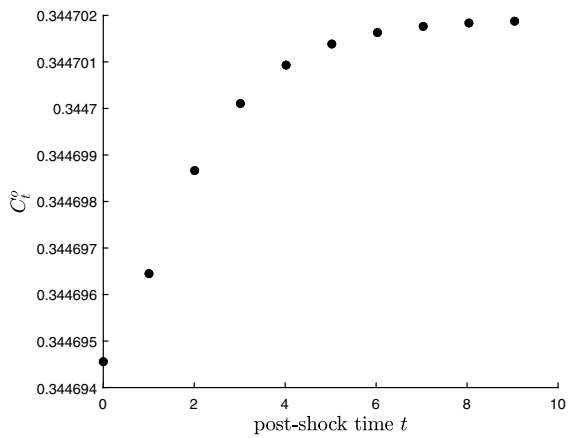

Fig. 4 Transition to the unique steady state with a linear regeneration function. Note The graphs plot the transitional dynamics in the different variables departing from the initial condition $\left(k_{0}, Q_{0}\right)=(0.1643,1.0005)$, which represents the polluted steady state in the unmanaged market equilibrium featuring a nonlinear regeneration function (see Table 3(b))

By construction multiple equilibria are a key feature of the unmanaged market economy. Indeed, as is shown in Table 3(b), the dirty steady-state equilibrium $\left(\mathrm{ME}_{d}\right)$ is virtually identical to its clean counterpart $\left(\mathrm{ME}_{c}\right)$ except in terms of environmental quality which drops from $\hat{Q}_{c}=2.5$ to $\hat{Q}_{d}=1.0005$. Private abatement 
is slightly higher and the net dirt flow is slightly lower in $\mathrm{ME}_{d}$ than in $\mathrm{ME}_{c}$. But these effects are not enough to cause a significant difference in the macroeconomic variables for the two equilibria. This is because $\hat{Q}_{d}$ lies far enough from the truly infernal region as shown in Fig. 2 above. The characteristic roots for the two stable steady state equilibria are, respectively $\left(\lambda_{1}, \lambda_{2}\right)=(0.2999,0.5454)$ for $\mathrm{ME}_{d}$ and $\left(\lambda_{1}, \lambda_{2}\right)=(0.2999,0.6388)$ for $\mathrm{ME}_{c}$. Hence both steady states are locally stable and the initial $\left(k_{0}, Q_{0}\right)$ combination determines which equilibrium the system converges to.

Numerical Result 2 (Existence and stability of the market equilibrium) For the benchmark parameterization given in Table 2 the dynamic system for the capital intensity $k_{t}$ and environmental quality $Q_{t}$ for the unmanaged market equilibrium is backward-looking stable (featuring characteristic roots inside the unit circle). With a linear regeneration function the equilibrium is unique and with a quintic function there are two Pareto-rankable equilibria differing predominantly in environmental quality.

\subsection{Social Optimum}

In the unmanaged market equilibrium the government does not engage in abatement activities whilst individuals do. Since environmental quality is a non-excludable and non-rival public good, the clean market equilibrium is unlikely to be socially optimal. In this section we characterize the deterministic first-best social optimum (DSO hereafter) both with a linear and a nonlinear regeneration function.

In the presence of overlapping generations the social welfare function must take a specific form in order to yield a dynamically consistent social optimum. Specifically, as was stressed by Calvo and Obstfeld (1988), it is imperative that the old generation in the planning period is treated appropriately by applying reverse discounting. In the context of our model, the social welfare function is given by $S W_{t} \equiv \sum_{\tau=0}^{\infty} \omega^{\tau-1} \Lambda_{t+\tau-1}^{y}$ which can be rewritten as:

$$
S W_{t}=\sum_{\tau=0}^{\infty} \omega^{\tau-1}\left[\ln c_{t+\tau-1}^{y}+\chi \ln m_{t+\tau-1}+\beta \ln c_{t+\tau}^{o}+\zeta \beta \ln Q_{t+\tau}\right],
$$

where $\omega$ is the social planner's discount factor $(0<\omega<1){ }^{4}$ Note that we impose symmetry up-front and express social welfare per young person (worker), of which there are $L$. The key aspect guaranteeing dynamic consistency is that lifetime utility of the current old generation is 'blown up' by the inverse of the social discount factor. Of course, at time $t$ the planner cannot influence the predetermined variables

\footnotetext{
${ }^{4}$ In our formulation of the social welfare function we adopt the traditional approach by respecting each individual's preferences. As is pointed out by Andreoni (2006, p. 1224) the choice of how to treat warmglow giving in social welfare is "as much a philosophical question as it is an economic one." Diamond (2006, pp. 909-910) and Andreoni (2006, p. 1227) propose excluding the warm-glow term in the social welfare function.
} 
$\left(c_{t-1}^{y}, m_{t-1}\right.$, and $\left.Q_{t}\right)$ but she can set the old-age consumption level $c_{t}^{o}$ and reverse discounting ensures that this choice will be made consistently.

The equality constraints faced by the social planner are:

$$
\begin{gathered}
k_{t+1}=f\left(k_{t}\right)+(1-\delta) k_{t}-c_{t}^{y}-c_{t}^{o}-m_{t}-g_{t}, \\
Q_{t+1}=H\left(Q_{t}\right)-D_{t}, \\
D_{t}=\xi L f\left(k_{t}\right) e^{\gamma L m_{t}-\eta L g_{t}},
\end{gathered}
$$

where $f\left(k_{t}\right)=\Omega k_{t}^{\alpha}$ is the intensive-form production function. In addition, the planner faces the following inequality constraint:

$$
g_{t} \geq 0 \text {. }
$$

Equation (37) is the resource constraint, (38) is the evolution equation for environmental quality, (39) defines the dirt flow, and (40) shows that public abatement must be non-negative.

At time $t$ the predetermined variables are $c_{t-1}^{y}, m_{t-1}, Q_{t}$, and $k_{t}$ and the choice variables of the planner are $c_{t+\tau}^{y}, c_{t+\tau}^{o}, m_{t+\tau}, Q_{t+1+\tau}, y_{t+\tau}, k_{t+1+\tau}, D_{t+\tau}$, and $g_{t+\tau}$ (for $\tau=0,1, \ldots)$. We show the details of the derivations in Supplementary Material (Online Appendix B) and focus here on the first-order conditions characterizing the interior solution for which public abatement is strictly positive. In addition to (37)-(39) they are:

$$
\begin{gathered}
\lambda_{t}^{k}=\frac{1}{c_{t}^{y}}=\frac{\beta}{\omega c_{t}^{o}}=\frac{\chi}{m_{t}}+\gamma L D_{t} \lambda_{t}^{q}, \\
\lambda_{t}^{k}=\omega\left[\left(f^{\prime}\left(k_{t+1}\right)+1-\delta\right) \lambda_{t+1}^{k}-\xi L f^{\prime}\left(k_{t+1}\right) e^{-\gamma L m_{t+1}-\eta L g_{t+1}} \lambda_{t+1}^{q}\right], \\
\lambda_{t}^{q}=\frac{\beta \zeta}{Q_{t+1}}+\omega H^{\prime}\left(Q_{t+1}\right) \lambda_{t+1}^{q}, \\
\lambda_{t}^{k}=\eta L D_{t} \lambda_{t}^{q},
\end{gathered}
$$

where $\lambda_{t}^{k}$ and $\lambda_{t}^{q}$ are the shadow prices of capital and environmental quality respectively. For given initial conditions $\left(k_{t}, Q_{t}\right)$, the perfect foresight solution selects unique time paths for $k_{t+1}, Q_{t+1}, c_{t}^{y}, c_{t}^{o}, m_{t}, g_{t}, \lambda_{t}^{k}$, and $\lambda_{t}^{q}$. In this section and the next we assume that the social planner's discount factor coincides with the discount factor of individuals $(\omega=\beta) .{ }^{5}$ The expressions in (41) imply that, in any given period, optimal consumption is the same for young and old individuals $\left(c_{t}^{y}=c_{t}^{o}\right.$ for all $\left.t\right)$.

\footnotetext{
${ }^{5}$ In Sect. 5 we discuss the implications of allowing $\beta$ and $\omega$ to differ.
} 
(a) Capital intensity $k_{t}$

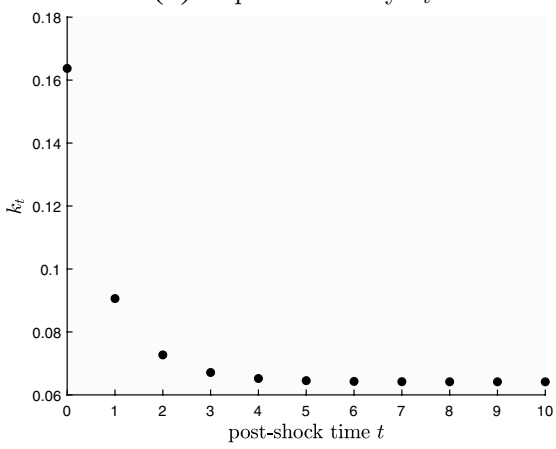

(c) Private abatement $m_{t}$

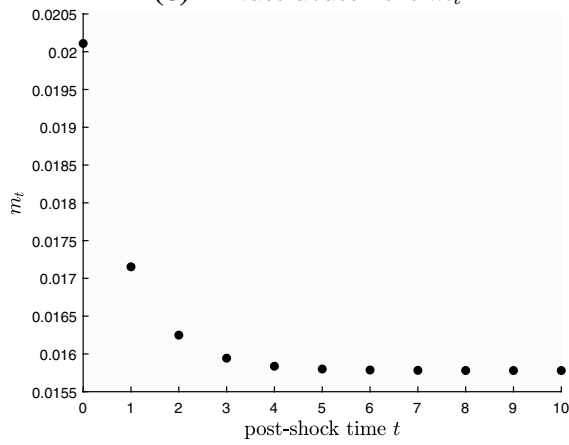

(e) Net dirt flow $D_{t}$

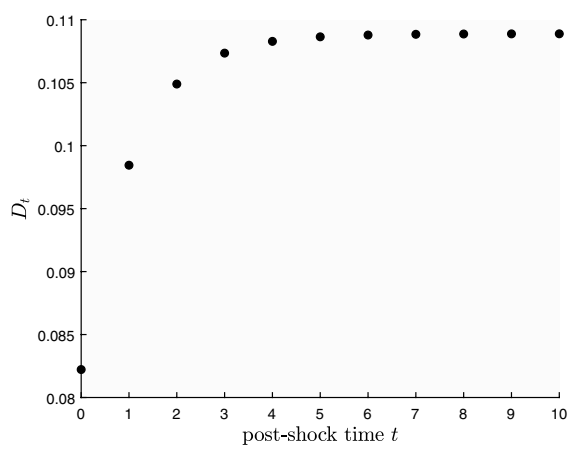

(b) Environmental quality $Q_{t}$

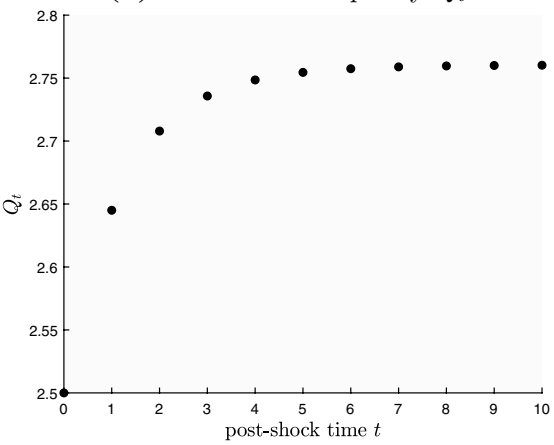

(d) Public abatement $g_{t}$

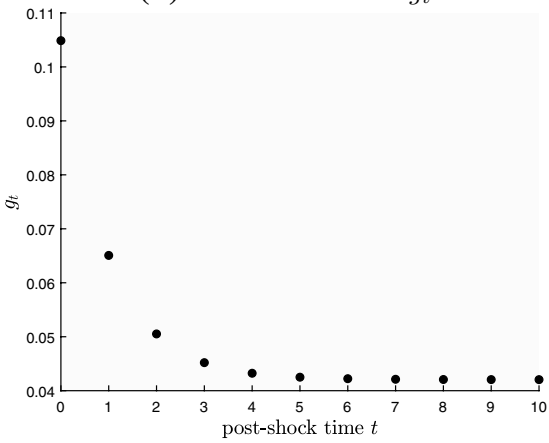

(f) Youth and old-age consumption $c_{t}^{y}=c_{t}^{o}$

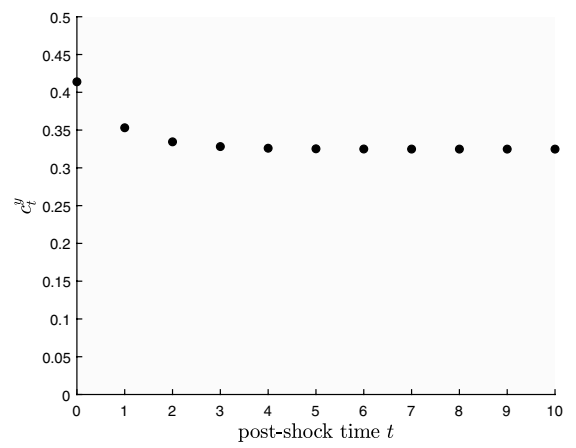

Fig. 5 From the unmanaged economy to the first-best social optimum

The final task at hand is to numerically characterize the DSO for the linear and nonlinear regeneration functions.

\subsubsection{Linear Environmental Dynamics}

With the linear regeneration function as stated in (33) above, the steady-state equilibrium in the unmanaged economy is unique-see scenario $\mathrm{ME}_{c}$ in Table 3(a). The 
key features of the DSO for this case have been reported in column (c) of that table. Even though the unmanaged market settles in a clean equilibrium, the DSO selects an even cleaner steady state than the market produces. It achieves this aim by (a) sharply reducing the capital intensity (and output per worker), (b) operating a sizeable program of public abatement (amounting to $5.58 \%$ of steady-state output), and (c) stimulating private abatement (which is almost six times higher in the DSO than in $\mathrm{ME}_{c}$ ).

Figure 5 visualizes the transition from $\mathrm{ME}_{c}$ to the first-best social optimum under a linear regeneration function. At the time of implementation of the policy initiative, the social planner proceeds at full throttle by selecting high values for both public and private abatement as well as consumption. This brings down the dirt flow and reduces the future capital intensity. Environmental quality improves dramatically in the next period after which the abatement instruments are reduced substantially. Over time transition in the capital intensity is relatively fast and monotonic, whilst adjustments in environmental quality are also monotonic but somewhat slower.

\subsubsection{Non-linear Environmental Dynamics}

With the nonlinear regeneration function as stated in (35) above, there exist two steady-state equilibria in the unmanaged economy - a clean one $\left(\mathrm{ME}_{c}\right)$ and a dirty one $\left(\mathrm{ME}_{d}\right)$. See columns (a) and (b) in Table 3. Just as for the linear case studied above, the DSO is unique in the nonlinear case also-see the results for scenario $\mathrm{DSO}_{n}$ in Table 3(d). Comparing columns (c) and (d) we observe that the only slight differences occur in the values selected for $Q, m, c^{y}=c^{o}$, and $D$. These differences occur because both the level and the slope of the regeneration function differ at the social optimum between the linear and nonlinear cases.

\section{Economic-Environmental Dynamics in a Stochastic World}

Up to this point we have followed standard practice in the literature by studying the economic-environmental dynamics in a deterministic world. In this section we broaden the horizon by moving to a stochastic setting. In particular, we assume that the difference equation for environmental quality is hit by random shocks in each period, i.e. Eq. (4) is replaced by:

$$
Q_{t+1}=H\left(Q_{t}\right)-\phi_{0}-D_{t}+\varepsilon_{t+1},
$$

where $\varepsilon_{t+1}$ is drawn from a lognormal distribution with mean $\phi_{0}$ and standard deviation $v$, and $H\left(Q_{t}\right)$ is a quintic function as given in (35) above. ${ }^{6}$ The random shock in the evolution equation for environmental quality ensures that young individuals are uncertain about the enjoyment they will derive from the environment when they are

\footnotetext{
6 To economize on space we restrict attention to the non-linear case in the main text. The case with a linear regeneration function is covered in Supplementary Material (Online Appendix C.1).
} 
old. It follows that the relevant objective function of a young individual is his/her expected utility:

$$
\mathbb{E}_{t}\left[\Lambda_{t}^{i}\right] \equiv \ln c_{t}^{y, i}+\chi \ln m_{t}^{i}+\beta \ln c_{t+1}^{o, i}+\beta \zeta \mathbb{E}_{t}\left[\ln Q_{t+1}\right],
$$

where $\mathbb{E}_{t}[x]$ stands for the expectation of $x$, conditional on information available at time $t$. In the absence of further sources of randomness the conditional mean future environmental quality is $\mathbb{E}_{t}\left[Q_{t+1}\right]=H\left(Q_{t}\right)-D_{t}$. It follows that a given realization of $\varepsilon_{t+1}$ has more impact on the individual's lifetime utility if $\mathbb{E}_{t}\left[Q_{t+1}\right]$ is low than if it is high.

\subsection{Unmanaged Market Equilibrium}

In the unmanaged market economy, government abatement and taxes are absent $\left(g_{t}=\tau_{t}=0\right.$ ), and young individual $i$ chooses $c_{t}^{y, i}, m_{t}^{i}, c_{t+1}^{o, i}$, and $s_{t}^{i}$ in order to maximize expected utility (46) subject to the lifetime budget constraint:

$$
c_{t}^{y, i}+m_{t}^{i}+\frac{c_{t+1}^{o, i}}{1+r_{t+1}}=w_{t}
$$

and the environmental transition function (45). The individual takes as given the abatement expenditures by other individuals, $M_{t}^{\neg i} \equiv \sum_{j \neq i}^{L} m_{t}^{j}$. The first-order conditions consist of (45), (47), and:

$$
\lambda_{t}=\frac{1}{c_{t}^{y, i}}=\frac{\beta\left(1+r_{t+1}\right)}{c_{t+1}^{o, i}}=\frac{\chi}{m_{t}^{i}}+\beta \zeta \frac{\partial \mathbb{E}_{t}\left[\ln Q_{t+1}\right]}{\partial m_{t}^{i}},
$$

where (5) and (45) imply that:

$$
\frac{\partial \mathbb{E}_{t}\left[\ln Q_{t+1}\right]}{\partial m_{t}^{i}}=\mathbb{E}_{t}\left[\frac{\gamma \xi L y_{t} e^{-\gamma\left(m_{t}^{i}+M_{t}^{i}\right)}}{H\left(Q_{t}\right)-\phi_{0}-\xi L y_{t} e^{-\gamma\left(m_{t}^{i}+M_{t}^{i}\right)}+\varepsilon_{t+1}}\right] .
$$

By invoking symmetry and recognizing the dependence of output and the wage rate on the capital intensity we find that the unmanaged market equilibrium is the solution to:

$$
\begin{gathered}
\frac{\chi}{m_{t}}+\beta \zeta \mathcal{M}\left(m_{t}, k_{t}, Q_{t}\right)=\frac{1+\beta}{(1-\alpha) \Omega k_{t}^{\alpha}-m_{t}}, \\
c_{t}^{y} \equiv \frac{(1-\alpha) \Omega k_{t}^{\alpha}-m_{t}}{1+\beta}, \\
k_{t+1}=(1-\alpha) \Omega k_{t}^{\alpha}-m_{t}-c_{t}^{y},
\end{gathered}
$$




$$
Q_{t+1}=H\left(Q_{t}\right)-\phi_{0}-\xi L \Omega k_{t}^{\alpha} e^{-\gamma L m_{t}}+\varepsilon_{t+1},
$$

where $\mathcal{M}\left(m_{t}, k_{t}, Q_{t}\right)$ is an auxiliary function defined as:

$$
\mathcal{M}\left(m_{t}, k_{t}, Q_{t}\right) \equiv \mathbb{E}_{t}\left[\frac{\gamma \xi L \Omega k_{t}^{\alpha} e^{-\gamma L m_{t}}}{H\left(Q_{t}\right)-\phi_{0}-\xi L \Omega k_{t}^{\alpha} e^{-\gamma L m_{t}}+\varepsilon_{t+1}}\right] .
$$

Equation (50) is a rewritten version of the first-order condition for private abatement using the expression for youth consumption, conditional on private abatement, as stated in (51). Equations (52) and (53) state the dynamic evolution of, respectively, the capital intensity and environmental quality conditional on private abatement.

The unmanaged market model is solved as follows. First, for given values of $k_{t}$ and $Q_{t}$ Eq. (50) is solved for optimal private abatement by simulating lognormally distributed random variables and conducting quasi Monte Carlo integration to compute the $\mathcal{M}\left(m_{t}, k_{t}, Q_{t}\right)$ function. This yields the 'policy' function $m_{t}=\mathbf{m}\left(k_{t}, Q_{t}\right)$. Second, by substituting $\mathbf{m}\left(k_{t}, Q_{t}\right)$ into (51)-(53) we obtain the policy functions for $c_{t}^{y}, k_{t+1}$, and $Q_{t+1}$ :

$$
\begin{gathered}
\mathbf{c}_{t}^{y}\left(k_{t}, Q_{t}\right) \equiv \frac{(1-\alpha) \Omega k_{t}^{\alpha}-\mathbf{m}\left(k_{t}, Q_{t}\right)}{1+\beta}, \\
\mathbf{k}^{+}\left(k_{t}, Q_{t}\right) \equiv(1-\alpha) \Omega k_{t}^{\alpha}-\mathbf{m}\left(k_{t}, Q_{t}\right)-\mathbf{c}_{t}^{y}\left(k_{t}, Q_{t}\right), \\
\mathbf{Q}^{+}\left(k_{t}, Q_{t}\right) \equiv H\left(Q_{t}\right)-\phi_{0}-\xi L \Omega k_{t}^{\alpha} e^{-\gamma L \mathbf{m}\left(k_{t}, Q_{t}\right)},
\end{gathered}
$$

where next period's capital intensity is deterministic, as $k_{t+1} \equiv \mathbf{k}^{+}\left(k_{t}, Q_{t}\right)$, and future environmental quality is stochastic, because $Q_{t+1}=\mathbf{Q}^{+}\left(k_{t}, Q_{t}\right)+\varepsilon_{t+1}$.

In Fig. 6 we illustrate simulated time paths for the main variables in the model as predicted by our model. We adopt a very long-run perspective by simulating one thousand periods. Since each period represents thirty years this amounts to thirty thousand years. Details concerning the computational aspects for these simulations are found in Supplementary Material (Online Appendix C). The key features of these simulations are as follows. First, environmental quality displays distinct and often long-lived epochs during which it is stuck fluctuating around either the clean or the dirty equilibrium. An unfortunate sequence of bad draws for $\varepsilon_{t+1}$ can push the system into the basin of attraction consistent with the polluted (low-welfare) stochastic equilibrium path. Since the government does not manage the economy, only a sequence of advantageous draws for $\varepsilon_{t+1}$ can get the system out of this trap. Second, whilst fluctuations in the capital intensity are rather small, they are asymmetric in the sense that there is an upper bound beyond which capital does not move. Intuitively, this asymmetry is caused by the fact that economic variables are only weakly dependent on $Q_{t}$ (cf. the stochastic generalization of Numerical Result 1) in combination with the result that the upper bound on environmental quality $(\bar{Q})$ occasionally becomes binding. The asymmetric pattern of fluctuations are also found in 
(a) Capital intensity $k_{t}$

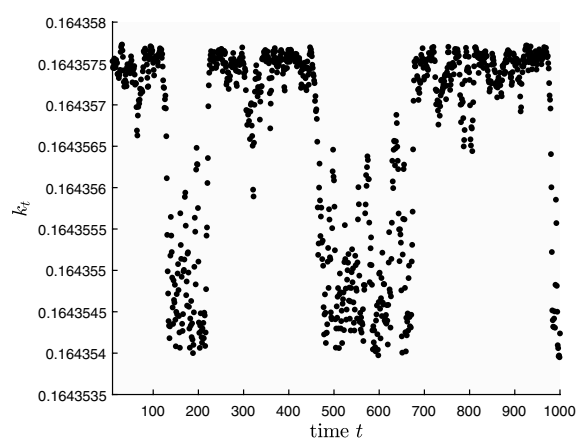

(c) Private abatement $m_{t}$



(e) Net dirt flow $D_{t}$

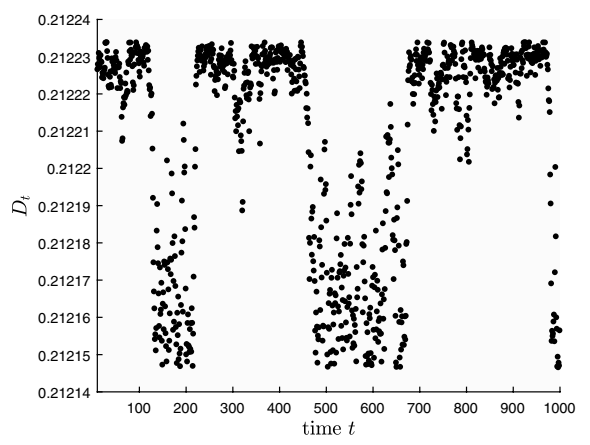

(b) Environmental quality $Q_{t}$

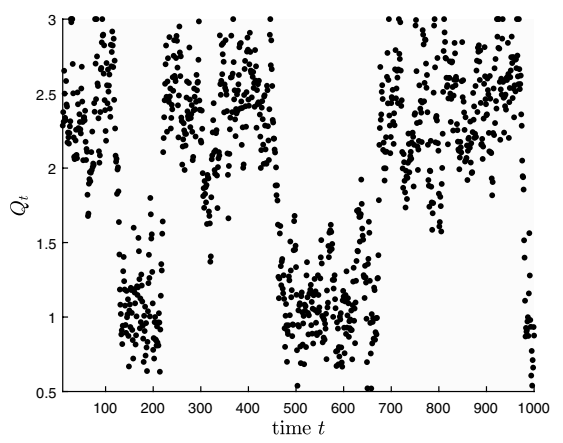

(d) Youth consumption $c_{t}^{y}$

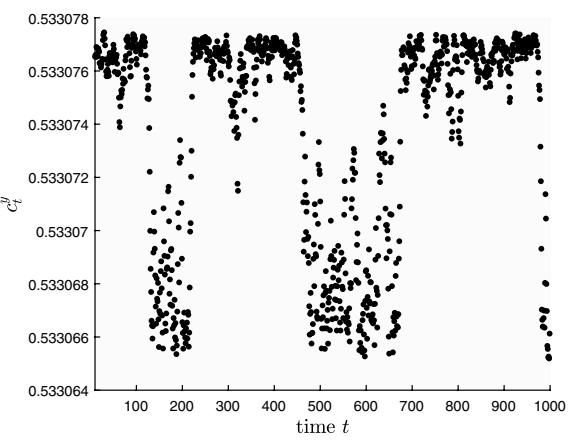

(f) Old-age consumption $c_{t}^{o}$

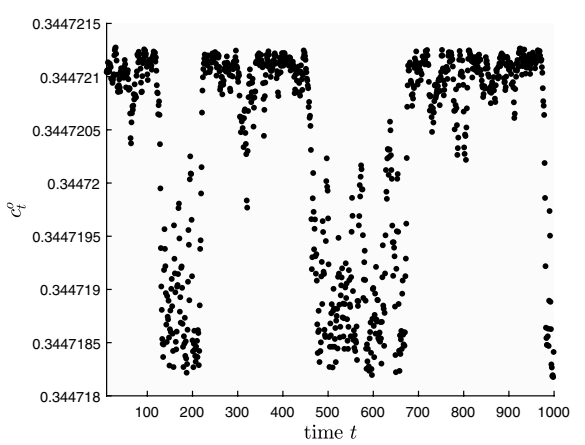

Fig. 6 The unmanaged economy in a stochastic world: long-run view

private abatement, youth- and old-age consumption, and the net dirt flow. Third, private abatement is considerably higher during high pollution epochs.

Since individuals care for the environment they do try to get out of a bad equilibrium by means of private abatement. To illustrate this mechanism further, Fig. 7 provides some visual information on the situation within a given high-pollution era. As is clear from panel (c) private abatement is higher than usual in the 
(a) Capital intensity $k_{t}$

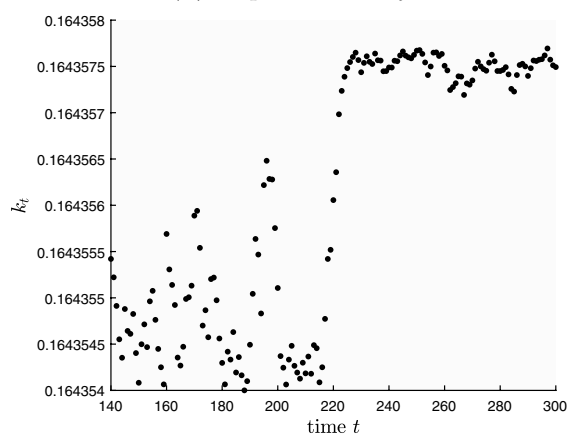

(c) Private abatement $m_{t}$

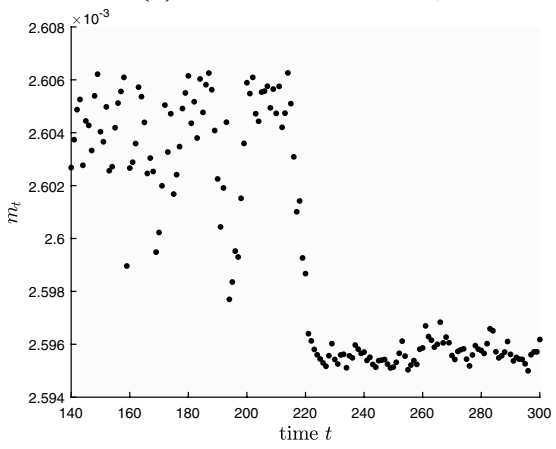

(e) Net dirt flow $d_{t}$

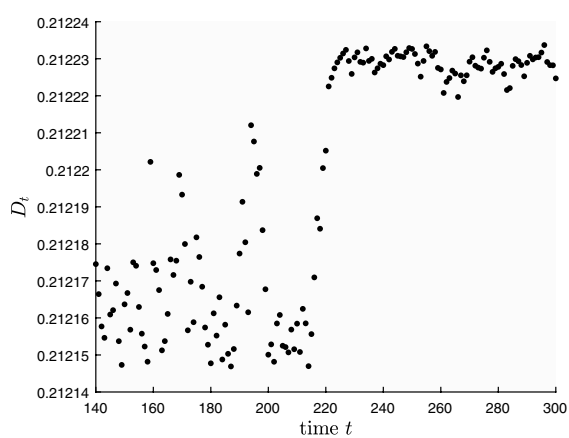

(b) Environmental quality $Q_{t}$

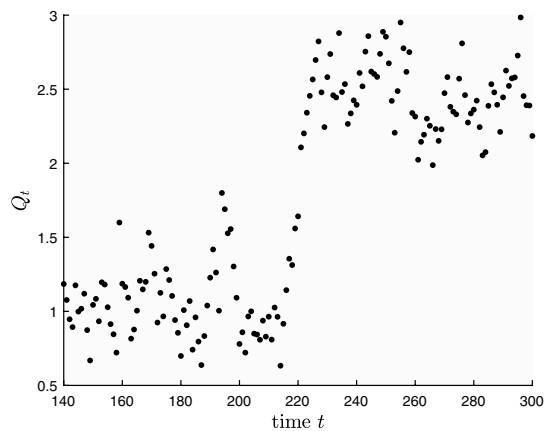

(d) Youth consumption $c_{t}^{y}$

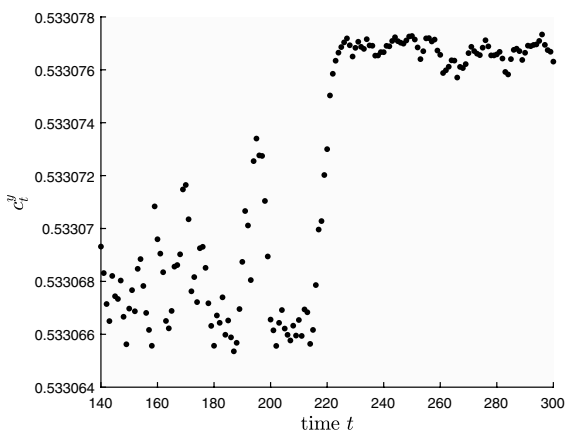

(f) Old-age consumption $c_{t}^{o}$

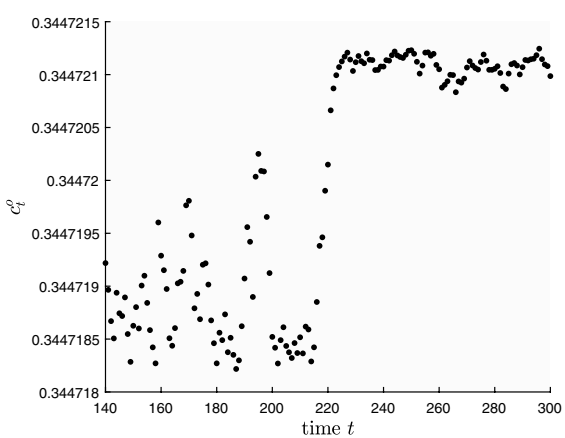

Fig. 7 The unmanaged economy in a stochastic world: bad times

polluted equilibrium but it is not sufficiently high to quickly return the system to a clean epoch-the warm glow effect is not powerful enough to do so. 


\subsection{Social Optimum}

Like individuals agents the social planner is unable to observe future environmental shocks. As a result the social welfare function as stated in (36) is augmented in a stochastic setting to:

$$
\begin{aligned}
\mathbb{E}_{t}\left[S W_{t}\right] & \equiv \mathbb{E}_{t} \sum_{\tau=0}^{\infty} \omega^{\tau-1}\left[\ln c_{t+\tau-1}^{y}+\chi \ln m_{t+\tau-1}+\beta \ln c_{t+\tau}^{o}+\zeta \beta \ln Q_{t+\tau}\right] \\
& =\frac{1}{\omega}\left[\ln c_{t-1}^{y}+\chi \ln m_{t-1}\right]+\mathbb{E}_{t} \sum_{\tau=0}^{\infty} S F\left(c_{t+\tau}^{y}, m_{t+\tau}, c_{t+\tau}^{o}, Q_{t+\tau}\right) \omega^{\tau},
\end{aligned}
$$

where the 'within-period' social felicity function is defined as follows:

$$
S F\left(c_{t+\tau}^{y}, m_{t+\tau}, c_{t+\tau}^{o}, Q_{t+\tau}\right) \equiv \ln c_{t+\tau}^{y}+\chi \ln m_{t+\tau}+\frac{\beta}{\omega}\left[\ln c_{t+\tau}^{0}+\zeta \ln Q_{t+\tau}\right] .
$$

Note that $S F(\cdot)$ differs from an individual's felicity function $\Lambda_{t}^{y, i}(\cdot)$ as stated in (1) above because the former contains only variables affecting individuals living in the same time period whereas the latter expresses lifetime utility over the life cycle of an individual and thus contains variables in adjacent periods. Note furthermore the subtle way in which the private and social discount factors interact in the social felicity function. Indeed, with disconnected generations and a dynamically consistent social welfare function the ratio of $\beta$ and $\omega$ determines the optimal division of a given consumption level $c_{t}$ over young and old people, i.e. the planner will always choose to set $c_{t}^{y} / c_{t}=\omega /(\beta+\omega)$ and $c_{t}^{o} / c_{t}=\beta /(\beta+\omega)$. So if the planner is more patient than individuals themselves $(\omega>\beta)$, then the young will receive a larger share of consumption than the old in the first-best optimum. ${ }^{7}$

By defining augmented social welfare as:

$$
A S W_{t} \equiv S W_{t}-\frac{1}{\omega}\left[\ln c_{t-1}^{y}+\chi \ln m_{t-1}\right],
$$

we find that $A S W_{t}$ can be written in a recursive format:

$$
A S W_{t}\left(k_{t}, Q_{t}\right)=S F\left(c_{t}^{y}, m_{t}, c_{t}^{o}, Q_{t}\right)+\omega \mathbb{E}_{t}\left[A S W_{t+1}\left(k_{t+1}, Q_{t+1}\right)\right] .
$$

The first-best social optimum can now be described using the tools of dynamic programming. The Bellman equation is given by:

\footnotetext{
${ }^{7}$ Much of the literature on environmental macroeconomics employs the representative-agent model and ignores the difference between private and social discounting. In contrast, by explicitly recognizing disconnected (and overlapping) generations our analysis provides a structural explanation for the form of the within-period felicity function that is used by a dynamically consistent social planner. See also Stern (2007, ch. 2) for a thorough discussion of both within-period felicity functions and social discounting.
} 
(a) Public abatement $\mathbf{g}\left(k_{t}, Q_{t}\right)$

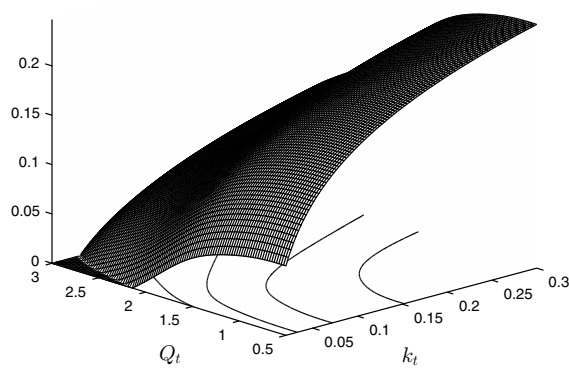

(c) Consumption $\mathbf{c}\left(k_{t}, Q_{t}\right)$

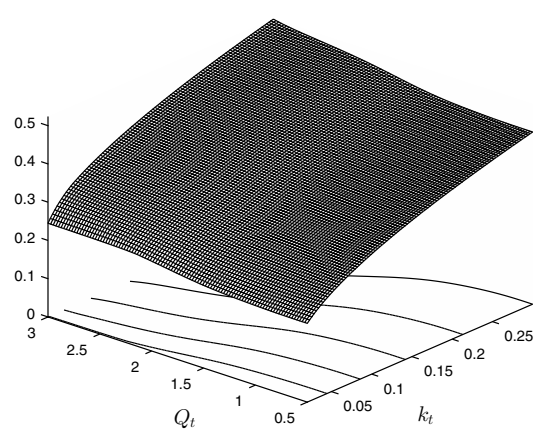

(b) Private abatement $\mathbf{m}\left(k_{t}, Q_{t}\right)$

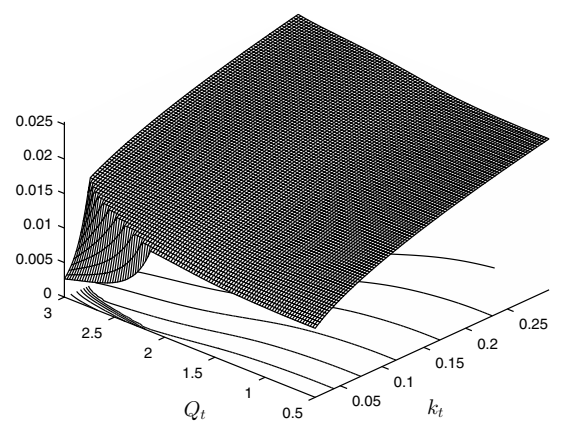

(d) Future capital intensity $\mathbf{k}^{+}\left(k_{t}, Q_{t}\right)$

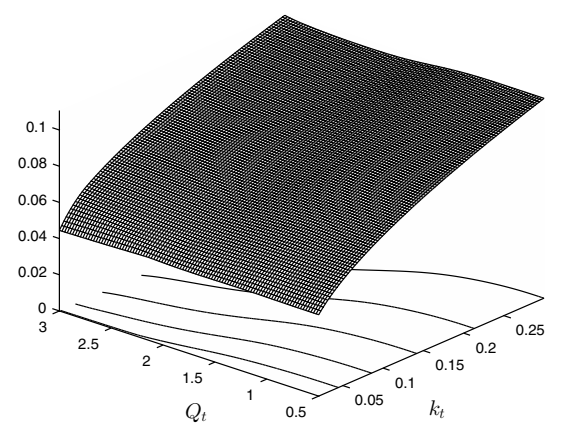

(e) Planned future environmental quality $\mathbf{Q}^{+}\left(k_{t}, Q_{t}\right)$

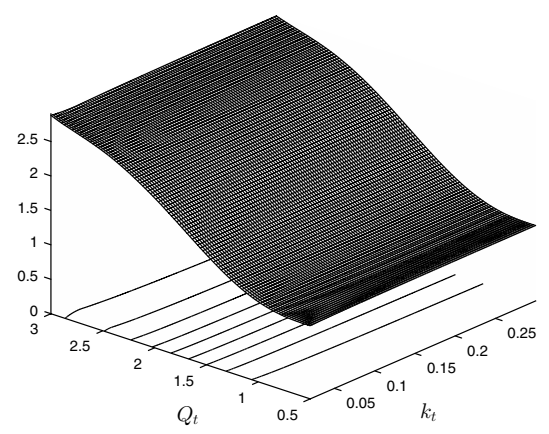

Fig. 8 Policy functions in the SSO 
(a) Public abatement $g_{t}$

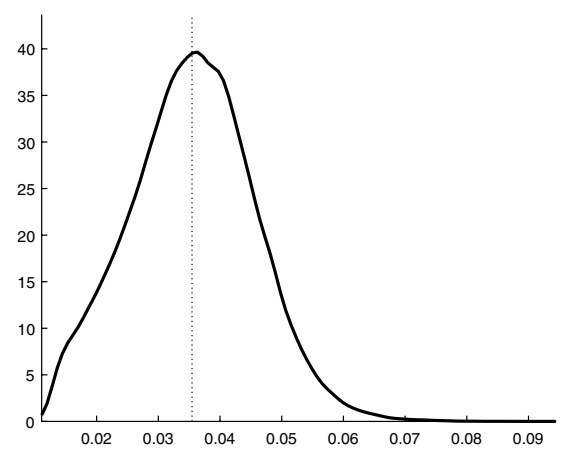

(c) Capital $k_{t}$

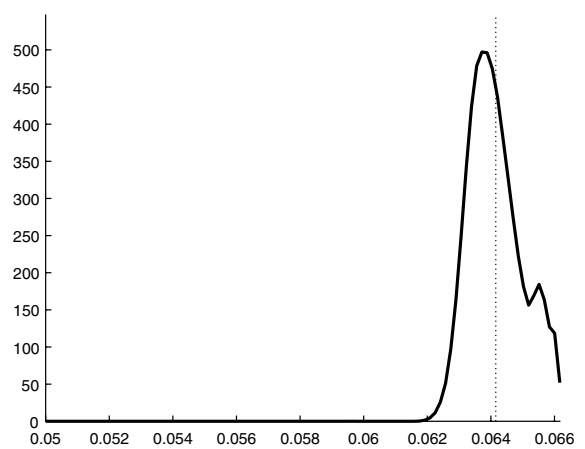

(b) Private abatement $m_{t}$

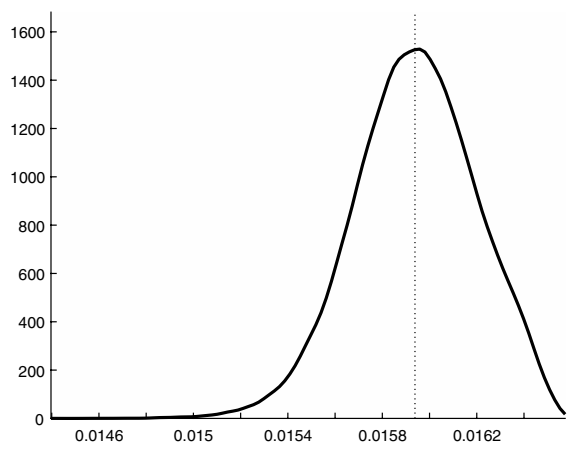

(d) Environmental quality $Q_{t}$

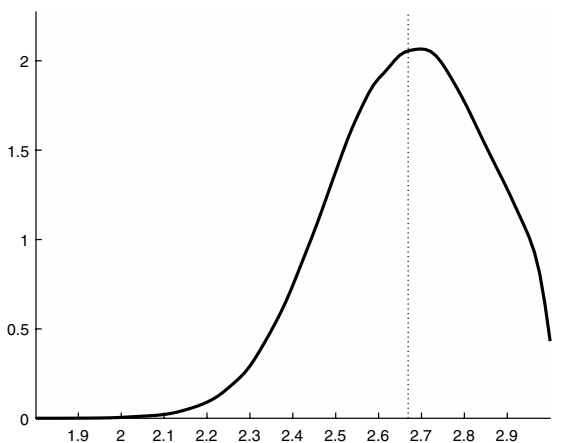

Fig. 9 Probability density functions in the SSO. Legend The figures plot the estimated probability density functions (PDF) for a number of key variables. The thin dashed lines represent the sample averages for these variables

$$
\begin{aligned}
\mathcal{V}\left(k_{t}, Q_{t}\right)= & \max _{\left\{c_{t}^{y}, m_{t}, c_{t}^{o}, g_{t}\right\}} S F\left(c_{t}^{y}, m_{t}, c_{t}^{o}, Q_{t}\right)+\omega \mathbb{E}_{t}\left[\mathcal{V}\left(k_{t+1}, Q_{t+1}\right)\right] \\
\text { s.t. } & k_{t+1}=f\left(k_{t}\right)+(1-\delta) k_{t}-c_{t}^{y}-c_{t}^{o}-m_{t}-g_{t} \\
& Q_{t+1}=H\left(Q_{t}\right)-\phi_{0}-D_{t}+\varepsilon_{t+1} \\
& D_{t} \equiv \xi L f\left(k_{t}\right) e^{-\gamma L m_{t}-\eta L g_{t}} \\
& g_{t} \geq 0 .
\end{aligned}
$$

where $c_{t}^{y}, m_{t}, c_{t}^{o}$, and $g_{t}$ are the control variables, $k_{t}$ and $Q_{t}$ are the state variables, and $\mathcal{V}\left(k_{t}, Q_{t}\right)$ is the value function.

In Fig. 8 we illustrate the policy functions for public abatement $g_{t}=\mathbf{g}\left(k_{t}, Q_{t}\right)$, private abatement $m_{t}=\mathbf{m}\left(k_{t}, Q_{t}\right)$, consumption $c_{t}^{y}=c_{t}^{o}=\mathbf{c}\left(k_{t}, Q_{t}\right)$, the future capital intensity $k_{t+1}=\mathbf{k}^{+}\left(k_{t}, Q_{t}\right)$, and the deterministic part of next period's environmental quality $Q_{t+1}-\varepsilon_{t+1}=\mathbf{Q}^{+}\left(k_{t}, Q_{t}\right)$. Details concerning the numerical approach adopted to compute these policy functions are found in Supplementary Material (Online Appendix C). The key features of these policy functions are as follows. First, for a given capital intensity public abatement (panel (a)) is 
decreasing in the quality of the environment and even becomes zero when $Q_{t}$ is high and $k_{t}$ is low. Second, for a given environmental quality public abatement is increasing in the capital intensity. Third, for a given capital intensity private abatement (panel (b)) is generally increasing in the quality of the environment. In a rich world blessed with a clean environment ( $k_{t}$ and $Q_{t}$ both high), the social planner finds it optimal to let private individuals engage in a relatively high level of private abatement. Matters are different when the capital intensity is low. In such a setting optimal private abatement is non-monotonic and becomes a downward sloping function of $Q_{t}$ beyond a high enough level of environmental quality. Fourth, optimal consumption (during youth and old-age) is increasing in both environmental quality and the capital intensity. Intuitively, in a polluted world the social planner finds it more important to spend resources on public abatement than on consumption or saving (compare panels (a), (c), and (d)). Fifth, for a given level of $Q_{t}$ the deterministic part of future environmental quality is virtually independent of the capital intensity.

In order to demonstrate the long-run statistical properties of the economic-ecological system run by a social planner we simulate the model for $T=10^{4}$ periods and use a kernel estimation method to compute the resulting probability density functions for the different choice variables. In Fig. 9a the PDF for public abatement is bell-shaped with $g_{t}$ ranging from its lower bound $\left(g_{t}=0\right)$ to about $g_{t}=0.07$. A social planner will thus conduct public abatement almost all of the time. In doing so the planner ensures that environmental quality will be high almost all the time, ranging from $Q_{t} \approx 2.1$ to its upper bound $\left(Q_{t}=\bar{Q}\right)$ as is shown in panel (d) of Fig. 9. Despite the fact that the fundamental difference equation for environmental quality features two (deterministic) steady states, the policy maker will ensure that fluctuations take place around the clean steady state. Panel (b) of Fig. 9 shows that there is substantial variability in the optimal level of private abatement. Finally, panel (c) shows that the capital intensity has a multi-modal PDF with a relatively tight support.

In Numerical Result 2 we have reported the stability of the deterministic core of our market equilibrium model. With a nonlinear regeneration function the inherent stability of the two equilibria gives rise to potentially long-lasting epochs of clean and dirty equilibria - see Fig. 6 In contrast, for the social planning solution the lowquality equilibrium is avoided. In order to provide some quantitative evidence on the time series properties of environmental quality for the market equilibrium and the social optimum we compute escape times. In particular, we study what is the expected time to move from $Q_{0}=1$ to $Q_{t} \geq 2.5$ ? And what is the expected time to move from $Q_{0}=2.5$ to $Q_{t} \leq 1$ ? (This is roughly from the bad equilibrium to the good equilibrium and vice versa.) Numerical Result 3 provides the answers (and Supplementary Material (Online Appendix C.3) shows how these escapte times have been computed). In the market equilibrium, switches are essentially random: since $Q_{t}$ is slightly closer to its threshold value in the bad state (than in the good state), it is slightly more likely to move from bad to good than vice versa. In contrast, in the first-best scenario, environmental quality moves quickly from bad to good and then never moves back. 
(a) Environmental quality $Q_{t}$

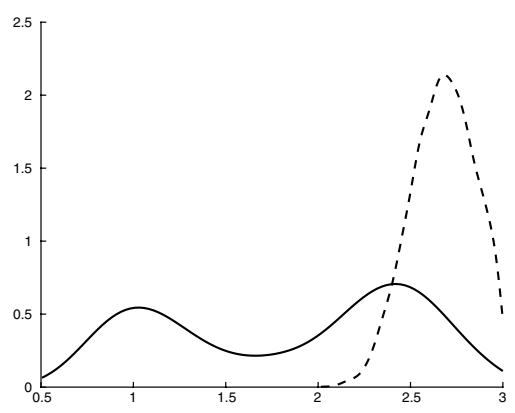

(b) Expected lifetime utility at birth $\mathbb{E}_{t}\left[\Lambda_{t}^{y}\left(k_{t}, Q_{t}\right)\right]$

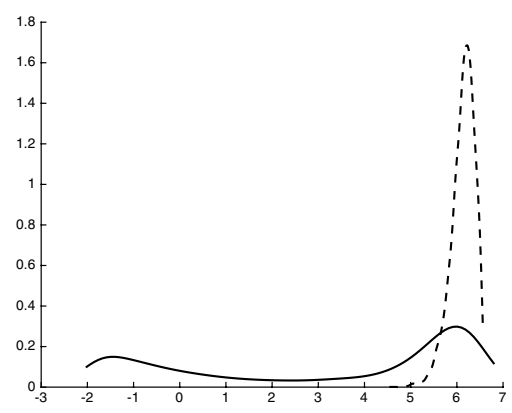

Fig. 10 The market or the planner?

Numerical Result 3 (Escape times) In the unmanaged stochastic market equilibrium it takes on average 101 periods for $Q_{t}$ to move from the bad state to the good state and 141 periods to move from the good state to the bad state. In the social planning equilibrium it takes on average 10 periods to move from the bad state to the good state and the opposite road remains untraveled.

\subsection{The Veil of Ignorance}

Up to this point in the paper we have restricted attention to two extreme scenarios, namely the messy and completely unmanaged laissez faire situation and the cerebral world of a benevolent social planner implementing the stochastic first-best social optimum (SSO). In a world hit by stochastic shocks there will be fluctuations in all the variables of interest to the individuals populating the economy. This prompts the following question. Given that stochastic fluctuation are a fact of life under both scenarios, in which world would you like to be born if you do not know the $\left(k_{t}, Q_{t}\right)$ combination that you will face at birth? Would you like to live in the turbulent world of the market economy or would you prefer the system managed by a social planner? To provide some perspective on this question we present Fig. 10 which depicts the PDFs for environmental quality, $Q_{t}$, and expected lifetime utility at birth, $\mathbb{E}_{t}\left[\Lambda_{t}^{y}\left(k_{t}, Q_{t}\right)\right]$, resulting in the market equilibrium (solid lines) and in the first-best social optimum (dashed lines). We recall from the preceding discussion that the two cases differ in two important dimensions. First, there is no public abatement in the market economy whereas such abatement is set optimally in the SSO. Second, in the market economy old-age consumption is determined by the individual agent during youth in the market economy. In contrast, in the SSO the social planner determines old-age consumption without any regard to what youth consumption was the period before.

The key features of Fig. 10 are as follows. First, in the unmanaged market economy the PDFs for environmental quality and expected utility at birth are both multimodal. This is, of course, consistent with the epochs that are clearly visible 
(a) Environmental quality $Q_{t}$

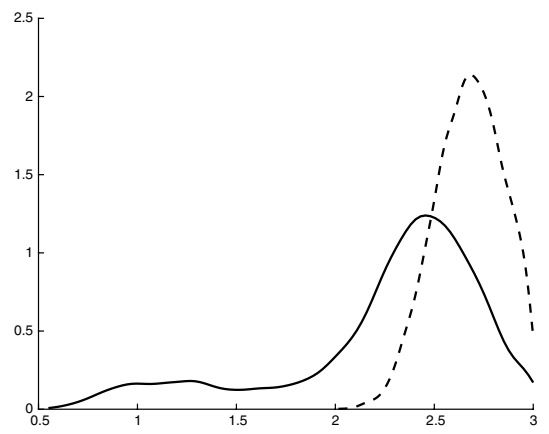

(b) Expected lifetime utility at birth $\mathbb{E}_{t}\left[\Lambda_{t}^{y}\right]$

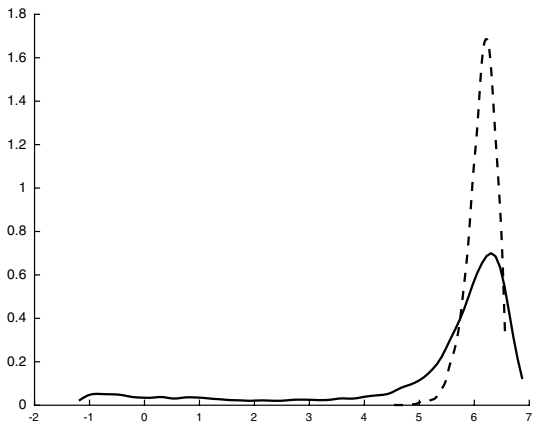

(c) Public abatement

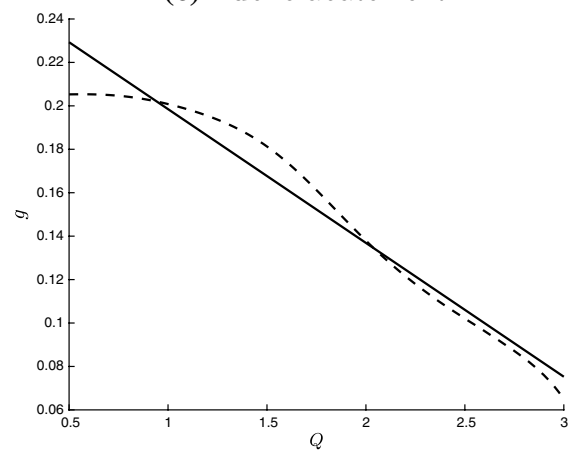

Fig. 11 Performance of an ad hoc public abatement policy rule

in the simulated time series displayed in Fig. 6b. Second, in the unmanaged market economy the supports of the distributions are quite wide, i.e. there exists a lot of inequality between generations and in that sense it matters a lot whether one is born during a clean epoch or in a polluted one. Third, in the SSO both distributions are single-peaked and their supports are relatively tight. Indeed, we find that there is absolutely no chance at all to be born in a polluted epoch in the SSO. In essence the social planner eliminates the polluted stochastic steady state by means of its abatement policy. Fourth, as is clear from Fig. 10b there is a small probability that a given ('very lucky') generation is better off under the unmanaged market economy than under the SSO. This unlikely event can occur if environmental quality is very close to its paradisiacal level $\left(Q_{t} \approx \bar{Q}\right)$. Since the social planner pursues intergenerational redistribution (in order to ensure that the co-existing old and young generations have the same consumption level) and the unmanaged market does not, a non-altruistic individual is better of in the unmanaged market economy in that specific case. 


\subsection{An Ad Hoc Policy Rule}

As is clear from the policy functions depicted in Fig. 8, the decentralization of the SSO is far from trivial. Indeed, in addition to calling for the optimal amount of public abatement (panel (a)), the SSO also aims to achieve the optimal distribution of resources between generations (such that $c_{t}^{y}=c_{t}^{o}$ for all $t$ in panel (c)) and to engineer the socially optimal amount of private abatement (panel (b)). As a result it may simply not be possible to implement the SSO in its full complexity in actual economies. For example, which instrument would the planner use to induce private individuals to pursue the correct amount of private abatement?

In this section we investigate whether and to what extent an ad hoc policy rule for public abatement could approximate the welfare gains that are achievable under the SSO. As we have argued above, both the capital intensity and private abatement have rather limited effects on the environment. This suggests that a policy rule for public abatement only should perform adequately.

The construction of the ad hoc rule proceeds as follows. First we note from Fig. 6a that fluctuations in the capital intensity are very small for the unmanaged market economy. Second, by setting $k_{t}$ equal to its long-run average $(\bar{k}=0.165)$ and taking a slice out of the surface of the policy function for public abatement in Fig. $8 \mathrm{a}$ we find the dashed line in Fig. 11c. The single-dimensional (average) policy function for public abatement is downward sloping and non-linear. Since environmental quality does not fall below $Q_{t}=0.5$ in the unmanaged market economy (see Fig. 6a) we restrict the domain for the policy function to the interval $[0.5, \bar{Q}]$. Third, by fitting a straight line though this average policy function we find the solid line in Fig. 11c. To summarize, the ad hoc policy rule is given by:

$$
g_{t}=\pi_{0}-\pi_{1} Q_{t},
$$

for $Q_{t} \in[0.5, \bar{Q}]$ and with $\pi_{0}=0.2601$ and $\pi_{1}=-0.0616$. Other than setting public abatement according to Eq. (63) the policy maker does not interfere in the economy or the environment.

In Fig. 11, panels (a) and (b) we compare the PDFs of the SSO (dashed lines) to the ones attained under the ad hoc public abatement rule (solid lines). Interestingly, under the ad hoc rule the distribution for environmental quality features a long and thin left-hand tail-see panel (a). Hence, the ad hoc rule makes environmental catastrophes unlikely but it does not succeed in ruling them out altogether. This also explains the pattern observed in panel (b) for expected utility at birth.

Numerical Result 4 (Rule-based abatement policy) An ad hoc linear policy rule relating public abatement to the state of environmental quality is suboptimal but nevertheless sharply reduces the risk of environmental catastrophes compared to the unmanaged market outcome. Under the rule it takes on average 324 periods for environmental quality to move from $Q_{t}=2.5$ to $Q_{t} \leq 1$ (from good to bad) and 52 periods to move from $Q_{t}=1$ to $Q_{t} \geq 2.5$ (from bad to good). 


\section{Robustness}

A key message of our analysis thus far is aptly visualized in Fig. 10a: in an unmanaged market economy the stationary distribution of environmental quality is bimodal (with peaks at low- and high-quality outcomes) but with a social planner at the helm this distribution is single-peaked and environmental catastrophes are practically impossible. Of course, these conclusions are not only model-specific but also depend critically on the values assigned to the model's structural parameters. As we acknowledged above in our discussion surrounding Table 2, whilst it is relatively easy to come up with plausible values for the key economic parameters $(\alpha, \beta$, and $\delta)$, it is not so straightforward to find evidence regarding the structural parameters characterizing the environmental effects in the model $(\gamma, \zeta, \eta, \xi$, and $\chi)$. Clearly, for the model calibration that we adopted we obtained the conclusions depicted in Fig. 10a. Simulations with alternative values for the key parameters confirm, however, that this conclusion is quite robust. Indeed, only for substantial changes in one or more of the parameters do we find that our message must be augmented. Our benchmark scenario is definitely not a knife-edge case in the high-dimensional parameter space. In the remainder of this section we discuss some of the most interesting cases that are found for different parameter configurations.

Variation 1: Does the capital intensity matter? One of the main differences between the market outcome (SUME) and the first-best (SSO) is that the former features a significantly higher capital intensity than the latter. Indeed, as is clear from Fig. 6a, c, average intensities are approximately 0.16 and 0.06 respectively. One could therefore argue that the unimodal distribution of environmental quality in the SSO in Fig. 10a is partly a result of the lower capital intensities (and lower dirt flows) and that it does not appear as a result of active interventions by the social planner. We investigate this issue by changing one (or more) parameter(s) in a step-wise fashion.

First, we increase the (individual) time preference rate from $4 \%$ to $7 \%$ on an annual basis. This reduces the private discount factor from $\beta=0.3083$ to $\beta=0.1314$. Of course, in an overlapping generations model such as ours, the effect of increasing impatience of individuals lowers household saving and thus the capital intensity in SUME. If we would also decrease the value of the social discount factor $\omega$, then the difference between the first best and the market equilibrium would be maintained. To circumvent this we keep $\omega$ at its benchmark value of $\omega=0.3083$. By only changing $\beta$ we obtain a rather unsurprising scenario under which there is essentially no risk of an environmental catastrophe. Indeed, as we illustrate in Fig. 12a, the stationary distributions for environmental quality are very similar for SUME and SSO ${ }^{8}$ With a low dirt flow in the SUME there is not much the social planner can improve upon.

\footnotetext{
8 The stationary distributions depicted in Fig. 12 have been obtained by using a computational method which computes an approximation to the optimal policy. See Supplementary Material (Online Appendix C.3) for details. This method approximates the actual solution quite well but is computationally much faster.
} 
(a)

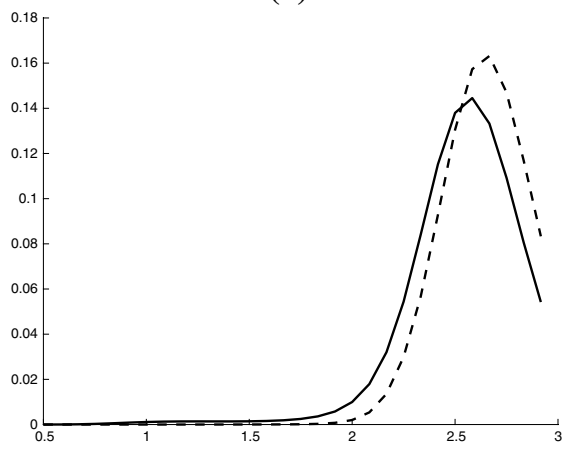

(c)

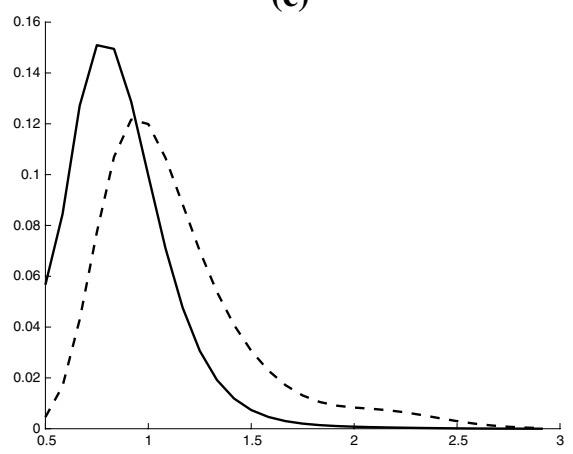

(e) social discounting $\omega$

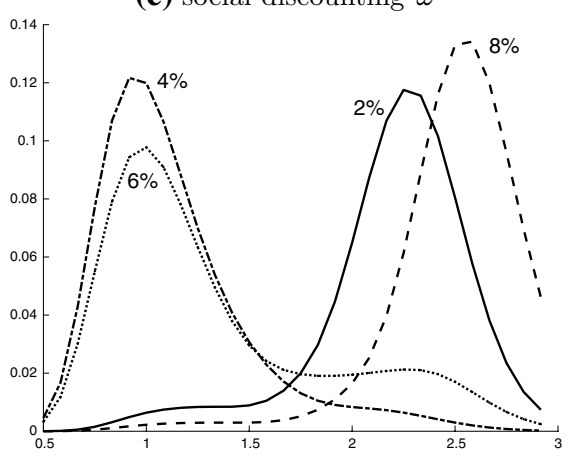

(b)

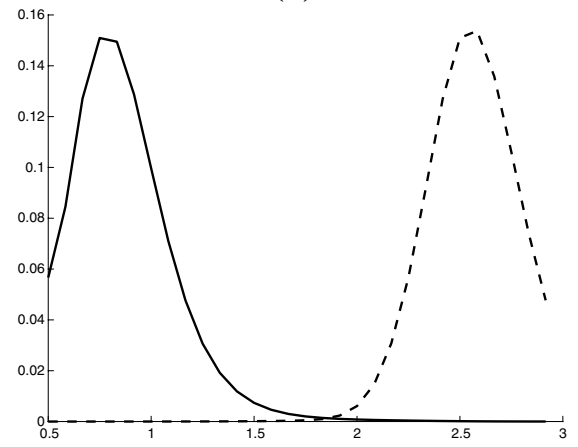

(d) group size $L$

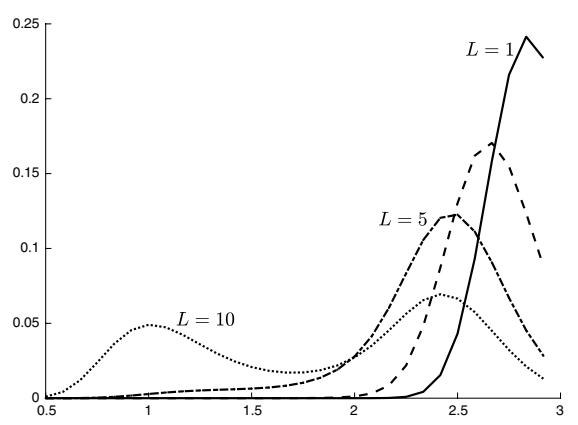

Fig. 12 Stationary distribution of environmental quality. Note In panels (a-c) the solid line depicts the unmanaged market outcome and the dashed line visualizes the first-best social optimum. In panel (d) the market outcome is drawn for different values of $L$. The social optimum is the dashed line. In panel (e) the social optimum is drawn for different values of the social discount factor $\omega$

Second, in order to keep the average dirt flow in SUME at roughly the same level as in the benchmark scenario we keep $\beta=0.3083$ (impatient individuals) but also double the value of $\xi$, from $\xi=2.3190 \times 10^{-3}$ to $\xi=4.6380 \times 10^{-3}$ (strong pollution effect). Figure $12 \mathrm{~b}$ shows the resulting stationary distributions of environmental 
quality. The first-best distribution is hardly changed from its benchmark profile, but the one for the market equilibrium is now unimodal with the peak at the low-quality equilibrium. It is easy to see why. In the first-best social optimum the average levels of private and public abatement are, respectively, 0.0212 and 0.0639 . In contrast, in the market equilibrium average private abatement only amounts to about 0.0023. The social planner is actively keeping the economy in the clean stochastic steady state. Private abatement in the unmanaged market is not able to ever attain this result.

Variation 2: Will the planner ever select the low-quality outcome? In all cases considered thus far the social planner consistently chooses to engineer the clean-environment outcome. This result is only reversed if individual do not have a very strong enjoyment from environmental quality. Consider, for example, the case in which $\beta=0.1314$ (impatient individuals) and $\xi=4.6380 \times 10^{-3}$ (strong pollution effect), but where at the same time the value of $\zeta$ is quartered from $\zeta=25$ to $\zeta=6.25$ (weak enjoyment effect). For this scenario we find that the social planner can will also engineer the low-quality stochastic equilibrium most of the time. Intuitively, if the importance that individuals themselves attach to environmental quality is reduced, then the social planner-who respects individual preferences-will also be content with being in the low-quality equilibrium for most of the time. This situation is illustrated in Fig. 12c.

Variation 3: Does free-riding matter? In the benchmark model we set the number of individuals in the economy equal to $L=100$ implying that each individual's contribution to environmental clean-up is quite small. Simply put, with a large number of agents there is significant scope for free-riding and it might be argued that SUME and SSO differ so much because the social planner internalizes this external effect. We investigate this claim by changing the number of agents. Specifically, we decrease the number of agents from $L=100$ via $L=10$ and $L=5$ to $L=1$. At the same time we scale up $\xi, \eta$ and $\gamma$ by a factor $100 / L$ in order to ensure that we are not reducing the size of the economy. Note that the first best does not change when we move the parameters in this fashion.

Although the change from $L=100$ to $L=10$ may seem quite substantial, it turns out that these cases are very similar. Indeed, as we illustrate in Fig. 12d, the distribution for environmental quality for $L=10$ is still bimodal under the market outcome. In order to get rid of the free-riding phenomenon it is necessary to have a really low number of agents. For $L=5$ the distribution under the market outcome is unimodal with the peak at the clean equilibrium. Interestingly, for $L=1$ average environmental quality even exceeds its first-best level! In that case effective average abatement (the weighted sum of private and government abatement) is 0.0186 in the market equilibrium and only 0.0030 in the first best. Note that the case with $L=1$ generalizes the John and Pecchenino (1994) and Prieur (2009) benchmark by including warm-glow preferences and stochastics. As in John and Pecchenino (1994, Proposition 1), our model implies that individual agents end up investing too much in a 
Table 4 Robustness checks

Number of individuals $L$

\begin{tabular}{llll}
\hline 100 & 10 & 5 & 1
\end{tabular}

\begin{tabular}{|c|c|c|c|c|}
\hline \multicolumn{5}{|l|}{ Panel (a) } \\
\hline Average public abatement & 0.0000 & 0.0000 & 0.0000 & 0.0000 \\
\hline Average private abatement & 0.0026 & 0.0041 & 0.0150 & 0.2448 \\
\hline Average youth consumption & 0.5352 & 0.5326 & 0.5196 & 0.2289 \\
\hline \multirow[t]{3}{*}{ Average capital intensity } & 0.1666 & 0.1651 & 0.1604 & 0.0711 \\
\hline & \multicolumn{4}{|c|}{ Social discount rate (annual) } \\
\hline & 0.0200 & 0.0400 & 0.0600 & 0.0800 \\
\hline \multicolumn{5}{|l|}{ Panel (b) } \\
\hline Average public abatement & 0.0962 & 0.0228 & 0.0394 & 0.0326 \\
\hline Average private abatement & 0.0241 & 0.0149 & 0.0088 & 0.0056 \\
\hline Average youth consumption & 0.4954 & 0.3360 & 0.1817 & 0.1150 \\
\hline Average capital intensity & 0.1758 & 0.0650 & 0.0253 & 0.0190 \\
\hline \multicolumn{5}{|l|}{ Panel (c) } \\
\hline Average government abatement & 0.0538 & 0.0197 & 0.0061 & 0.0145 \\
\hline Average private abatement & 0.0317 & 0.0221 & 0.0115 & 0.0076 \\
\hline Average youth consumption & 0.6518 & 0.4675 & 0.3187 & 0.1867 \\
\hline Average capital intensity & 0.1758 & 0.0646 & 0.0298 & 0.0131 \\
\hline
\end{tabular}

In panel (a) the group size $L$ is varied. In panels (b) and (c) the degree of impatience of the social planner (as captured by the social discount rate) is varied. The corresponding values for the social discount factor $\omega$ are $0.5521,0.3083,0.1741$, and 0.0994 . In panel (b) the private discount factor is held constant at its benchmark value of $\beta=0.3083$ (see Table 2). In panel (c) the private discount factor is set equal to $\beta=0.1314$ (or 7 percent per annum). The value of $\xi$ is doubled, from $\xi=2.3190 \times 10^{-3}$ to $\xi=4.6380 \times 10^{-3}$, whilst the value of $\zeta$ is quartered, from $\zeta=25$ to $\zeta=6.25$

clean environment (at the expense of youth consumption, which is 0.3360 on average in the first best versus 0.2289 in the market equilibrium).

Variation 4: Does the planner's patience matter? As a final robustness check we consider the effect of changing the social discount factor $\omega$. We keep all other parameters at their benchmark values. Making the social planner more (or less) patient has little effect on the distribution of environmental quality (the distribution remains single-peaked at roughly the same value as in the benchmark). Intuitively this happens because, in the benchmark, we are relatively far away from the flipping point. To get a better idea of what is happening for different values of $\omega$, we refer to Table 4(b) in which we report results for average public and private abatement, youth consumption, and the capital intensity for different values of $\omega$ (consistent with social discount rates ranging from 2 to 8 percent per annum). As the social planner becomes more impatient, private abatement, youth consumption, and the capital intensity are all reduced. Note that a very patient planner (featuring a social discount rate of 2 percent) ensures that the average capital intensity is even higher 
than under the market equilibrium. Environmental quality remains single-peaked even for this case because the planner ensures that both private and public abatement are substantial.

In Table 4(c) we consider the alternative scenario in which individuals are relatively impatient (such that $\beta=0.1314$, an annual rate of time preference of 7 percent). At the same time we double the value of $\xi$ (from $2.3190 \times 10^{-3}$ to $4.6380 \times 10^{-3}$ ) and quarter the value of $\zeta$ (from 25 to 6.25). (This parameter setting was also adopted in Variation 3 above.) Interestingly, as is illustrated in Fig. 12e, the social planner mostly selects the clean stochastic equilibrium for both very high and very low values of $\omega$, though for different reasons. For very low values of $\omega$ there is a lot of pollution but the social planner engages in large amounts of government abatement to avoid flipping. In contrast, for very high values of $\omega$, social impatience leads to a low average capital intensity and hence a low risk of flipping (thus obviating the need for much public or private abatement). In the intermediate case (featuring discount rate of 4 or 6 percent), the planner mostly selects the low-quality stochastic equilibrium-see Fig. 12e and Table 4(c).

\section{Conclusions}

In this paper we have studied the interactions between the environment and the macroeconomic system employing a stochastic overlapping generations model of the Diamond-Samuelson type. In the absence of government policies and with a nonlinear environmental regeneration function, the stochastic unmanaged market economy displays often long-lasting epochs during which environmental quality remains very high whilst at other times the ecological system is trapped fluctuating around a highly polluted equilibrium. Even though individuals care for the environment they are unable to avoid such low-welfare epochs thus opening up a useful role for government intervention.

A dynamically consistent social planner operating with the same information set as the public will ensure that the low-quality trap is eliminated altogether. In the social optimum the policy maker conditions the allocation at each time on the pre-existing capital intensity and environmental quality. Since we assume that public abatement is more efficient than private abatement, the policy function for public abatement (evaluated for the average capital intensity) is strongly decreasing in pre-existing environmental quality whilst the one for private abatement displays the opposite pattern. Intuitively, if environmental quality is very low then it is optimal for the government to conduct abatement. In contrast, if environmental quality is high then the marginal gains due to public abatement are low and it is advantageous to let individual agents engage in more private abatement for which they gain direct utility due to the warm-glow motive. Surprisingly, an ad hoc linear rule for public 
abatement which is only conditioned on the pre-existing quality of the environment captures most of the benefits attained under the first-best policy.

In this paper we have deliberately restricted attention to stochastic shocks affecting the environmental state equation. In future work we intend to introduce additional randomness in the form of productivity shocks affecting the economic system. Such shocks should have a non-trivial influence on optimal environmental policy. Indeed, on the one hand a positive productivity shock increases output and wages (which enhances welfare) but on the other hand it also increases the pollution inflow (which reduces welfare). We expect to find that part of the increase in wages will be used to increase public abatement in the first-best social optimum.

Acknowledgements The first author thanks the Center for Economic Studies in Munich for the excellent hospitality experienced during his research visit in November-December 2017. Technical advice by Allard van der Made on Markov chains and the implied stationary distributions is gratefully acknowledged.

Open Access This article is licensed under a Creative Commons Attribution 4.0 International License, which permits use, sharing, adaptation, distribution and reproduction in any medium or format, as long as you give appropriate credit to the original author(s) and the source, provide a link to the Creative Commons licence, and indicate if changes were made. The images or other third party material in this article are included in the article's Creative Commons licence, unless indicated otherwise in a credit line to the material. If material is not included in the article's Creative Commons licence and your intended use is not permitted by statutory regulation or exceeds the permitted use, you will need to obtain permission directly from the copyright holder. To view a copy of this licence, visit http://creativecommons.org/licen ses/by/4.0/.

\section{References}

Andreoni, J. (1988). Privately provided public goods in a large economy: The limits of altruism. Journal of Public Economics, 35, 57-73.

Andreoni, J. (1989). Giving with impure altruism: Applications to charity and Ricardian Equivalence. Journal of Political Economy, 97, 1447-1458.

Andreoni, J. (1990). Impure altruism and donations to public goods: A theory of warm-glow giving. Economic Journal, 100, 464-477.

Andreoni, J. (2006). Philanthropy. In S.-C. Kolm \& J. M. Ythier (Eds.), Handbook of the economics of giving, altriusm and reciprocity (Vol. 2). Amsterdam: North-Holland.

Andreoni, J., \& Levinson, A. (1990). The simple analytics of the environmental Kuznets curve. Journal of Public Economics, 80, 269-286.

Barro, R. J. (1974). Are government bonds net wealth? Journal of Political Economy, 82, 1095-1117.

Bernheim, B. D., \& Bagwell, K. (1988). Is everything neutral? Journal of Political Economy, 96, 308-338.

Brock, W. A., \& Starrett, D. (2003). Managing systems with non-convex positive feedback. Environmental and Resource Economics, 26, 575-602.

Cai, Y., Judd, K. L., \& Lontzek, T. S. (2013). The social cost of stochastic and irreversible climate change. Working Paper 18704, NBER, Cambridge.

Calvo, G. A., \& Obstfeld, M. (1988). Optimal time-consistent fiscal policy with finite lifetimes. Econometrica, 56, 411-432.

de Zeeuw, A., \& Li, C.-Z. (2016). The economics of tipping points. Environmental and Resource Economics, 65, 603-624.

Diamond, P. A. (2006). Optimal tax treatment of private contributions for public goods with and without warm glow preferences. Journal of Public Economics, 90, 897-919. 
Grass, D., Kiseleva, T., \& Wagener, F. (2015). Small-noise asymptotics of Hamilton-Jacobi-Bellman equations and bifurcations of stochastic optimal control problems. Communications in Nonlinear Science and Numerical Simulation, 22, 38-54.

Heijdra, B. J., \& Heijnen, P. (2013). Environmental abatement policy and the macroeconomy in the presence of ecological thresholds. Environmental and Resource Economics, 55, 47-70.

Heijdra, B. J., \& Heijnen, P. (2014). Optimal environmental policy in the presence of multiple equilibria and reversible hysteresis. In E. Moser, W. Semmler, G. Tragler, \& V. M. Veliov (Eds.), Dynamic Optimization in Environmental Economics (pp. 61-85). Berlin: Springer.

Heijnen, P., \& Dam, L. (2019). Catastrophe and cooperation. Dynamic Games and Applicatons, 9, $122-141$.

John, A., \& Pecchenino, R. A. (1994). An overlapping generations model of growth and the environment. Economic Journal, 104, 1393-1410.

Lemoine, D., \& Traeger, C. (2014). Watch your step: Optimal policy in a tipping climate. American Economic Journal: Economic Policy, 6, 137-166.

Mäler, K.-G., Xepapadeas, A., \& de Zeeuw, A. (2003). The economics of shallow lakes. Environmental and Resource Economics, 26, 603-624.

Muradian, R. (2001). Ecological thresholds: A survey. Ecological Economics, 38, 7-24.

Nordhaus, W. D. (2013). The climate casino: Risk, uncertainty, and economics for a warming world. New Haven, CT: Yale University Press.

Polasky, S., de Zeeuw, A., \& Wagener, F. (2011). Optimal management with potential regime shifts. Journal of Environmental Economics and Management, 62, 229-240.

Prieur, F. (2009). The environmental Kuznets curve in a world of irreversibility. Economic Theory, 40, 57-90.

Scheffer, M., Carpenter, S., Foley, J. A., Folke, C., \& Walker, B. (2001). Catastrophic shifts in ecosystems. Nature, 413, 591-596.

Stern, N. (2007). The economics of climate change. Cambridge: Cambridge University Press.

Stern, N. (2015). Why are we waiting? The logic, urgency, and promise of tackling climate change. Cambridge, MA: MIT Press.

Tsur, Y., \& Zemel, A. (1996). Accounting for global warming risks: Resource management under event uncertainty. Journal of Economic Dynamics and Control, 20, 1289-1305.

Tsur, Y., \& Zemel, A. (1998). Pollution control in an uncertain environment. Journal of Economic Dynamics and Control, 22, 961-975.

Tsur, Y., \& Zemel, A. (2006). Welfare measurement under threats of environmental catastrophes. Journal of Environmental Economics and Management, 52, 421-429.

van der Ploeg, F. (2014). Abrupt positive feedback and the social cost of carbon. European Economic Review, 67, 28-41.

van der Ploeg, F., \& de Zeeuw, A. (2016). Non-cooperative and cooperative responses to climate catastrophes in the global economy: A North-South perspective. Environmental and Resource Economics, 65, 519-540.

van der Ploeg, F., \& de Zeeuw, A. (2018). Climate tipping points and economic growth: Precautionary capital and the price of carbon. Journal of the European Economic Association, 16, 1577-1617.

World Commission of Environment and Development. (1987). Our common future (Brundtland report). Oxford: Oxford University Press.

\section{Affiliations}

\section{Ben J. Heijdra ${ }^{1,2,3} \cdot$ Pim Heijnen ${ }^{1}$}

Pim Heijnen

p.heijnen@rug.nl

1 Faculty of Economics and Business, University of Groningen, P.O. Box 800, 9700 AV Groningen, The Netherlands

2 CESifo, Munich, Germany

3 Netspar, Tilburg, The Netherlands 